\title{
System Characterization Report on the China-Brazil Earth Resources Satellite-4A (CBERS-4A)
}

Chapter J of

System Characterization of Earth Observation Sensors

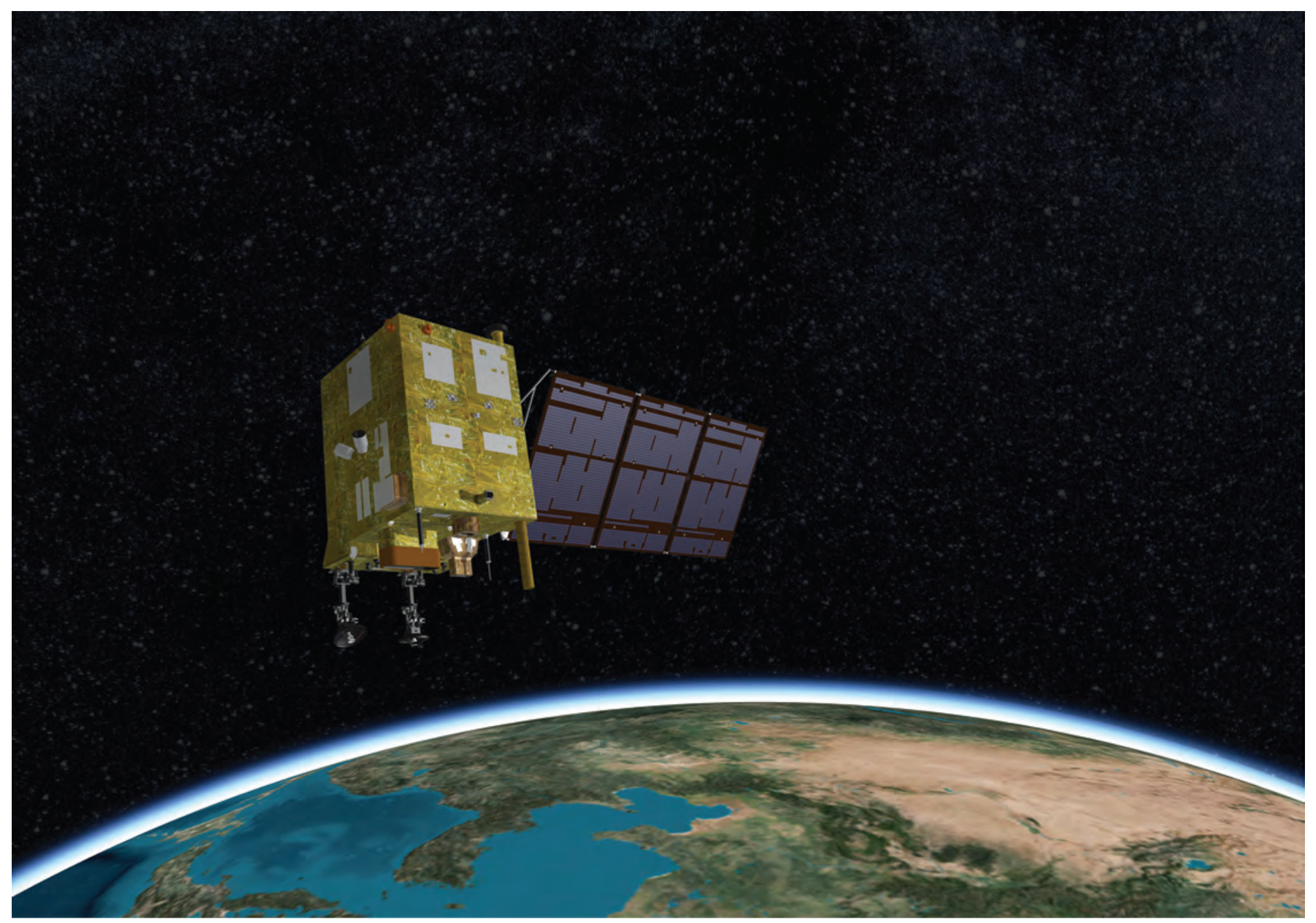

Open-File Report 2021-1030-J 
Cover: Artist rendition of the China-Brazil Earth Resources Satellite-4A. Image by the National Institute for Space Research. Image of Asia from Analytical Graphics, Inc., Systems Tool Kit. 


\section{System Characterization Report on the China-Brazil Earth Resources Satellite-4A (CBERS-4A)}

By James C. Vrabel, ${ }^{1}$ Gregory L. Stensaas, ${ }^{2}$ Cody Anderson, ${ }^{2}$ Jon

Christopherson, ${ }^{3}$ Minsu Kim, ${ }^{3}$ Seonkyung Park, ${ }^{3}$ and Simon Cantrell ${ }^{3}$

${ }^{1}$ Imaging Technology Consultants, Inc., under contract to the

U.S. Geological Survey.

${ }^{2}$ U.S. Geological Survey.

${ }^{3} \mathrm{KBR}$, Inc., under contract to the U.S. Geological.

Open-File Report 2021-1030-J 


\section{U.S. Geological Survey, Reston, Virginia: 2021}

For more information on the USGS - the Federal source for science about the Earth, its natural and living resources, natural hazards, and the environment—visit https://www.usgs.gov or call 1-888-ASK-USGS.

For an overview of USGS information products, including maps, imagery, and publications, visit https://store.usgs.gov/.

Any use of trade, firm, or product names is for descriptive purposes only and does not imply endorsement by the U.S. Government.

Although this information product, for the most part, is in the public domain, it also may contain copyrighted materials as noted in the text. Permission to reproduce copyrighted items must be secured from the copyright owner.

Suggested citation:

Vrabel, J.C., Stensaas, G.L., Anderson, C., Christopherson, J., Kim, M., Park, S., and Cantrell, S., 2021, System characterization report on the China-Brazil Earth Resources Satellite-4A (CBERS-4A), chap. J of Ramaseri Chandra, S.N., comp., System characterization of Earth observation sensors: U.S. Geological Survey Open-File Report 2021-1030, 35 p., https://doi.org/10.3133/ofr20211030J.

ISSN 2331-1258 (online) 


\section{Contents}

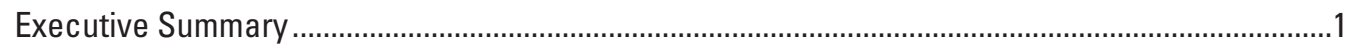

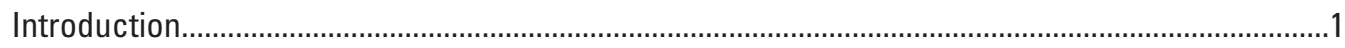

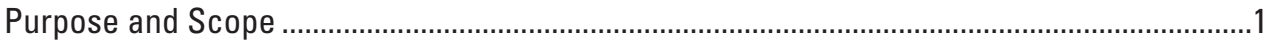

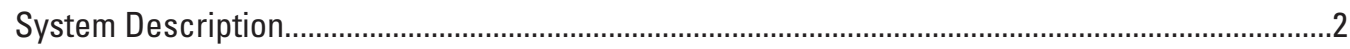

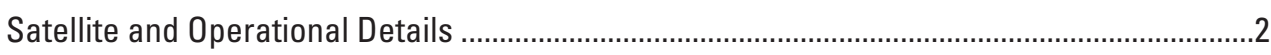

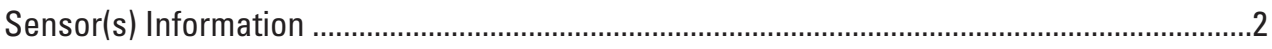

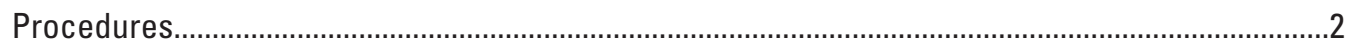

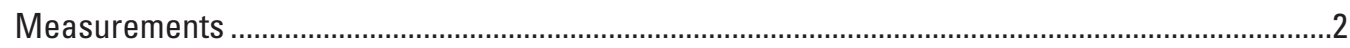

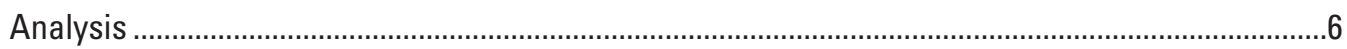

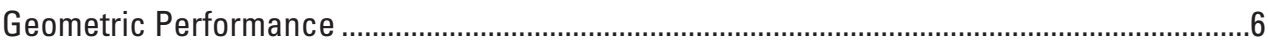

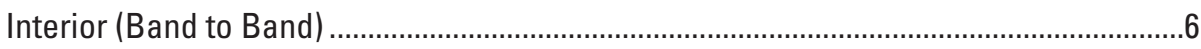

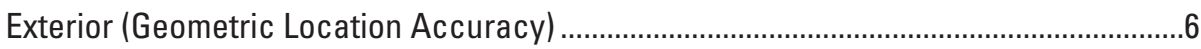

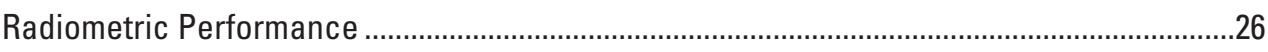

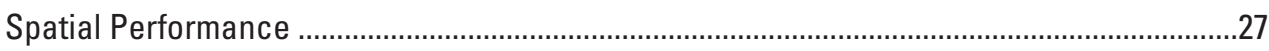

Summary and Conclusions....................................................................................................

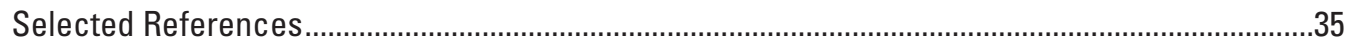

\section{Figures}

1. Graph showing China-Brazil Earth Resources Satellite-4A multispectral camera

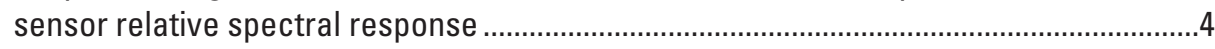

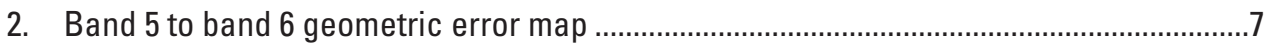

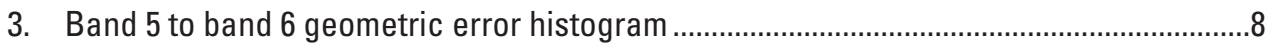

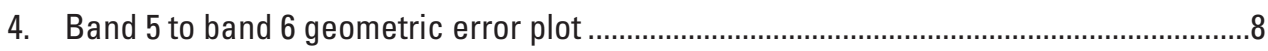

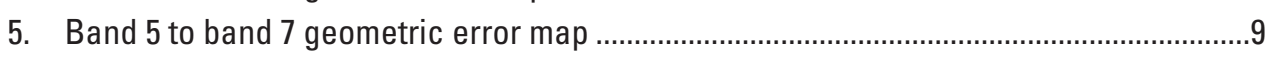

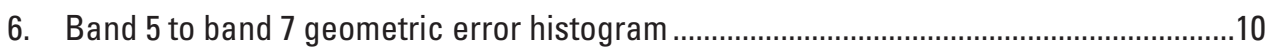

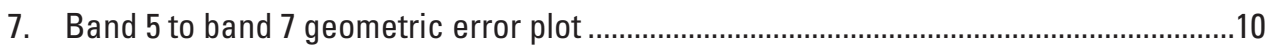

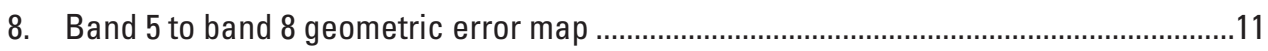

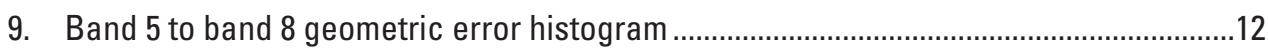

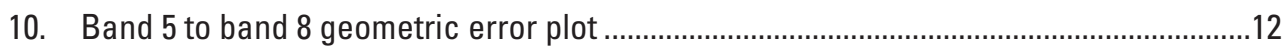

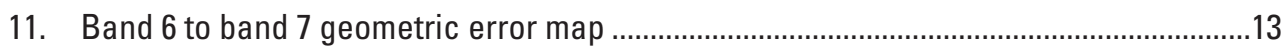

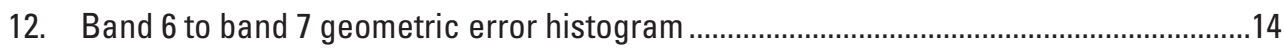

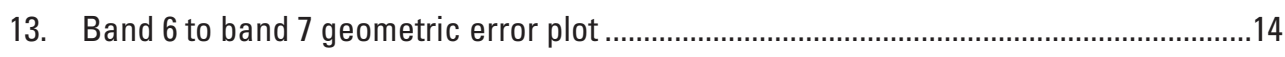

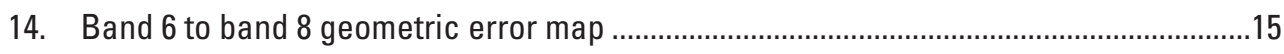

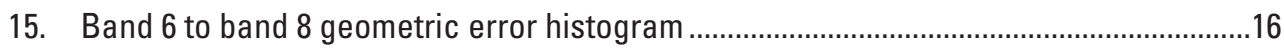

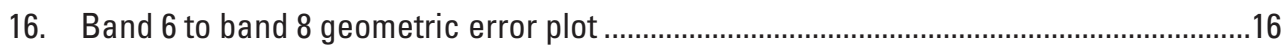

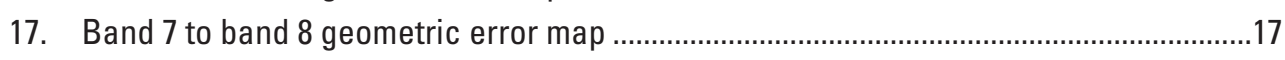

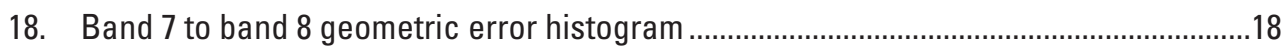

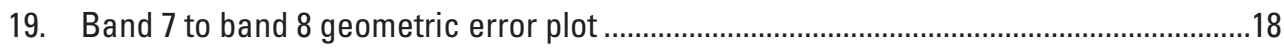

20. Map showing relative geometric error comparison for Landsat 8 Operational Land Imager and China-Brazil Earth Resources Satellite-4A .........................................20

21. Relative geometric easting and northing error histogram comparison for Landsat 8 Operational Land Imager and China-Brazil Earth Resources Satellite-4A .....21 
22. Relative geometric easting and northing error plot comparison for Landsat 8

Operational Land Imager and China-Brazil Earth Resources Satellite-4A ......................21

23. Map showing relative geometric error comparison for Landsat 8 and China-Brazil Earth Resources Satellite-4A...

24. Relative geometric easting and northing error histogram comparison for Landsat 8 Operational Land Imager and China-Brazil Earth Resources Satellite-4A.....23

25. Relative geometric easting and northing error plot comparison for Landsat 8 Operational Land Imager and China-Brazil Earth Resources Satellite-4A ......................23

26. Map showing relative geometric error comparison for Landsat 8 and China-Brazil Earth Resources Satellite-4A...

27. Relative geometric easting and northing error histogram comparison for Landsat 8 Operational Land Imager and China-Brazil Earth Resources Satellite-4A.....25

28. Relative geometric easting and northing error plot comparison for Landsat 8 Operational Land Imager and China-Brazil Earth Resources Satellite-4A ......................25

29. Graphs showing Top of Atmosphere reflectance comparison for Landsat 8 Operational Land Imager and China-Brazil Earth Resources Satellite-4A ...

30. Graphs showing Top of Atmosphere reflectance comparison for Landsat 8 Operational Land Imager and China-Brazil Earth Resources Satellite-4A.

31. Graphs showing Top of Atmosphere reflectance comparison for Landsat 8 Operational Land Imager and China-Brazil Earth Resources Satellite-4A

32. China-Brazil Earth Resources Satellite-4A image region of interest selected for spatial analysis.

33. Graphs showing band 5 raw edge transects and aligned transects 30

34. Graphs showing band 5 edge spread function and line spread function and modulation transfer function

35. Graphs showing band 6 raw edge transects and aligned transects. 31

36. Graphs showing band 6 edge spread function and line spread function and modulation transfer function...

7. Graphs showing band 7 raw edge transects and aligned transects...

38. Graphs showing band 7 edge spread function and line spread function and

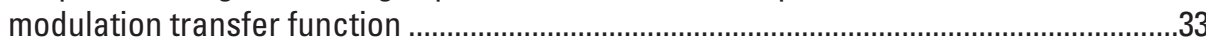

39. Graphs showing band 8 raw edge transects and aligned transects ...............................34

40. Graphs showing band 8 edge spread function and line spread function and modulation transfer function

\section{Tables}

1. Satellite and operational details for China-Brazil Earth Resources Satellite-4A...............3

2. Imaging sensor details for China-Brazil Earth Resources Satellite-4A ..............................

3. U.S. Geological Survey measurement results for China-Brazil Earth Resources Satellite-4A

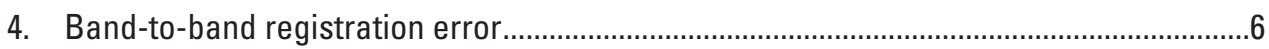

5. Geometric error of China-Brazil Earth Resources Satellite-4A relative to Landsat 8 .....19

6. Top of Atmosphere reflectance comparison of China-Brazil Earth Resources Satellite-4A against Landsat 8 Operational Land Imager .

7. Spatial performance of China-Brazil Earth Resources Satellite-4A 


\section{Conversion Factors}

International System of Units to U.S. customary units

\begin{tabular}{|c|c|c|}
\hline Multiply & By & To obtain \\
\hline \multicolumn{3}{|c|}{ Length } \\
\hline meter (m) & 3.281 & foot (ft) \\
\hline meter (m) & 1.094 & yard (yd) \\
\hline
\end{tabular}

\section{Abbreviations}

CBERS-4A China-Brazil Earth Resources Satellite-4A

ECCOE EROS Cal/Val Center of Excellence

EROS Earth Resources Observation and Science

EROSSC EROS System Characterization

GSD ground sample distance

JACIE Joint Agency Commercial Imagery Evaluation

NIR near infrared

OLI Operational Land Imager

USGS U.S. Geological Survey 



\title{
System Characterization Report on the China-Brazil Earth Resources Satellite-4A (CBERS-4A)
}

\author{
By James C. Vrabel, ${ }^{1}$ Gregory L. Stensaas, ${ }^{2}$ Cody Anderson, ${ }^{2}$ Jon Christopherson, ${ }^{3}$ Minsu Kim, ${ }^{3}$ Seonkyung \\ Park, ${ }^{3}$ and Simon Cantrell ${ }^{3}$
}

\section{Executive Summary}

This report addresses system characterization of the China-Brazil Earth Resources Satellite-4A (CBERS-4A) multispectral remote sensing satellite and is part of a series of system characterization reports produced and delivered by the U.S. Geological Survey Earth Resources Observation and Science Cal/Val Center of Excellence in 2021. These reports present and detail the methodology and procedures for characterization; present technical and operational information about the specific sensing system being evaluated; and provide a summary of test measurements, data retention practices, data analysis results, and conclusions.

CBERS-4A is a joint Chinese-Brazilian mediumresolution satellite launched in December 2019 by the China National Space Agency/National Institute for Space Research (Brazil) on a Chang Zheng 4B rocket from the Taiyuan Satellite Launch Center for Earth resources monitoring. The CBERS-4A mission continues the CBERS mission that has been in continual operation since the launch of CBERS-1 in 1999.

The CBERS-4A satellite was designed and built by Academia Chinesa de Tecnologia Espacial/National Institute for Space Research and uses the Phoenix-Eye bus. CBERS-4A carries the multispectral camera and wide field imager sensors for medium-resolution land imaging and the wide swath panchromatic and multispectral camera sensor for high-resolution land imaging. This assessment focused on the multispectral camera sensor only. More information on CBERS sensors is available in the "2020 Joint Agency Commercial Imagery Evaluation-Remote Sensing Satellite Compendium" and at http://www.cbers.inpe.br/lancamentos/cbers04a.php.

The Earth Resources Observation and Science Cal/Val Center of Excellence system characterization team completed data analyses to characterize the geometric (interior and exterior), radiometric, and spatial performances. Results of these analyses indicate that CBERS-4A provides an interior

\footnotetext{
${ }^{1}$ Imaging Technology Consultants, Inc., under contract to the U.S. Geological Survey.

${ }^{2}$ U.S. Geological Survey.

${ }^{3} \mathrm{KBR}$, Inc., under contract to the U.S. Geological Survey.
}

(band-to-band) geometric performance in the range of -0.02 to -0.16 pixel; an exterior geometric accuracy performance of -22.02 ( -1.47 pixels) to -16.06 meters $(-1.07$ pixels $)$; a radiometric accuracy performance of -0.006 to 0.925 (offset and slope); and a spatial performance for relative edge response in the range of 0.39 to 0.44 , for full width at half maximum in the range of 2.38 to 2.56 pixels, and for a modulation transfer function at a Nyquist frequency in the range of 0.001 to 0.013 .

\section{Introduction}

The multispectral camera sensor onboard the ChinaBrazil Earth Resources Satellite-4A (CBERS-4A) multispectral remote sensing satellite is a medium-resolution land observation instrument consisting of four bands: blue, green, red, and near infrared (NIR). CBERS-4A is a joint Chinese-Brazilian medium-resolution satellite launched in December 2019 by the China National Space Agency/National Institute for Space Research (Brazil) on a Chang Zheng 4B rocket from the Taiyuan Satellite Launch Center for Earth resources monitoring. The CBERS-4A mission continues the CBERS mission that has been in continual operation since the launch of CBERS-1 in 1999. The primary missions of CBERS include monitoring deforestation, water resources, agriculture, urban growth, and land use.

The data analysis results provided within this report have been derived from approved Joint Agency Commercial Imagery Evaluation (JACIE) processes and procedures. JACIE was formed to leverage resources from several Federal agencies for the characterization of remote sensing data and to share those results across the remote sensing community. More information about JACIE is available at https:/www.usgs.gov/ core-science-systems/eros/calval/jacie?qt-science_support_ page_related_con $=3 \#$ qt-science_support_page_related_con.

\section{Purpose and Scope}

The purpose of this report is to describe the specific sensor or sensing system, test its performance in three categories, complete related data analyses to quantify these performances, 
and report the results in a standardized document. In this chapter, the CBERS-4A sensor is described. The performance testing of the system is limited to geometric, radiometric, and spatial. The scope of the geometric assessment is limited to testing the interior alignments of spectral bands against each other, and the exterior alignment is tested in reference to Landsat 8 Operational Land Imager (OLI).

The U.S. Geological Survey (USGS) Earth Resources Observation and Science (EROS) Cal/Val Center of Excellence (ECCOE) project, and the associated system characterization process used for this assessment, follows the USGS Fundamental Science Practices, which include maintaining data, information, and documentation needed to reproduce and validate the scientific analysis documented in this report. Additional information and guidance about Fundamental Science Practices and related resource information of interest to the public are available at https://www .usgs.gov/about/organization/science-support/office-sciencequality-and-integrity/fundamental-science-practices. For additional information related to the report, please contact ECCOE at eccoe@usgs.gov.

\section{System Description}

This section describes the satellite and operational details and provides information about CBERS-4A.

\section{Satellite and Operational Details}

The satellite and operational details for CBERS-4A are listed in table 1 .

\section{Sensor(s) Information}

Imaging sensor details are listed in table 2. Sensor relative spectral responses are shown in figure 1.

\section{Procedures}

The USGS ECCOE has established standard processes to identify Earth observing systems of interest and to assess the geometric, radiometric, and spatial qualities of data products from these systems.

The assessment steps are as follows:

- system identification and investigation to learn the general specifications of the satellite and its sensor(s);

- data receipt and initial inspection to understand the characteristics and any overt flaws in the data product so that it may be further analyzed;

- geometry characterization, including interior geometric orientation measuring the relative alignment of spectral bands and exterior geometric orientation measuring how well the georeferenced pixels within the image are aligned to a known reference;

- radiometry characterization, including assessing how well the data product correlates with a known reference and, when possible, assessing the signal-to-noise ratio; and

- spatial characterization, assessing the two-dimensional fidelity of the image pixels to their projected ground sample distance (GSD).

Data analysis and test results are maintained at the USGS EROS Center by the ECCOE project.

\section{Measurements}

The observed USGS measurements are listed in table 3. Physical error, in meters, is calculated by the GSD (15-meter [m] band to band; 30.0-m image to image) multiplied by the pixel error. Details about the methodologies used are outlined in the "Analysis" section. 
Table 1. Satellite and operational details for China-Brazil Earth Resources Satellite-4A (CBERS-4A).

[DN, descending node; kg, kilogram; NIR, near infrared; W, watt; Mbps, megabits per second; km, kilometer; ${ }^{\circ}$, degree; min, minute; \pm , plus or minus; m, meter]

\begin{tabular}{|c|c|}
\hline Product information & CBERS-4A data \\
\hline \multicolumn{2}{|r|}{ Satellite and operational information } \\
\hline Product name & CBERS-4A MUX Level 4 DN (orthorectified product) \\
\hline Sensor name(s) & MUX (multispectral camera) \\
\hline Lift-off mass & $1,730 \mathrm{~kg}$ \\
\hline Sensor type & Multispectral, visible, and near infrared (blue, green, red, NIR) \\
\hline Scanning technique & Pushbroom \\
\hline Power & Solar array generating 2,100 W (MUX sensor requires $66 \mathrm{~W}$ ) \\
\hline Data rate & $68 \mathrm{Mbps}$ \\
\hline Mission type & Land monitoring Earth resources mission (focused on Amazon region) \\
\hline Operators & $\begin{array}{l}\text { INPE (Instituto Nacional de Pesquisas Espaciais) and } \\
\text { CAST (Academia Chinesa de Tecnologia Espacial) }\end{array}$ \\
\hline \multicolumn{2}{|r|}{ Operational details } \\
\hline Operating orbit & Sun synchronous, near circular \\
\hline Orbital altitude range & $628.8 \mathrm{~km}$ \\
\hline Sensor angle altitude & $97.9^{\circ}$ inclination \\
\hline Altitude and orbit control & 3-axis body stabilized using reaction wheels, magnetic torquers, and hydrazine thrusters \\
\hline Orbit period & $97.25 \mathrm{~min}$ \\
\hline Imaging time & 10:30 descending node \\
\hline Data pricing & Free \\
\hline Product abstract & http://www.cbers.inpe.br/lancamentos/cbers04a.php \\
\hline Product locator & http://www2.dgi.inpe.br/catalogo/explore \\
\hline
\end{tabular}

Table 2. Imaging sensor details for China-Brazil Earth Resources Satellite-4A (CBERS-4A).

[Sensor name is CBERS-4A multispectral camera; swath width is 90 kilometers; $\mu \mathrm{m}$, micrometer; $\mathrm{m}$, meter; NIR, near infrared]

\begin{tabular}{lcccc}
\hline \multirow{2}{*}{ Spectral band(s) details } & \multicolumn{4}{c}{ CBERS-4A } \\
\cline { 2 - 5 } & Lower band $(\boldsymbol{\mu m})$ & $\begin{array}{c}\text { Upper band } \\
(\boldsymbol{\mu m})\end{array}$ & $\begin{array}{c}\text { Radiometric resolution } \\
(\mathbf{b i t s})\end{array}$ & $\begin{array}{c}\text { Ground sample distance } \\
(\mathbf{m})\end{array}$ \\
\hline Band 5-blue & 0.45 & 0.52 & 8 & 16 \\
Band 6-green & 0.52 & 0.59 & 8 & 16 \\
Band 7-red & 0.63 & 0.69 & 8 & 16 \\
Band 8-NIR & 0.77 & 0.89 & 8 & 16 \\
\hline
\end{tabular}


1.2

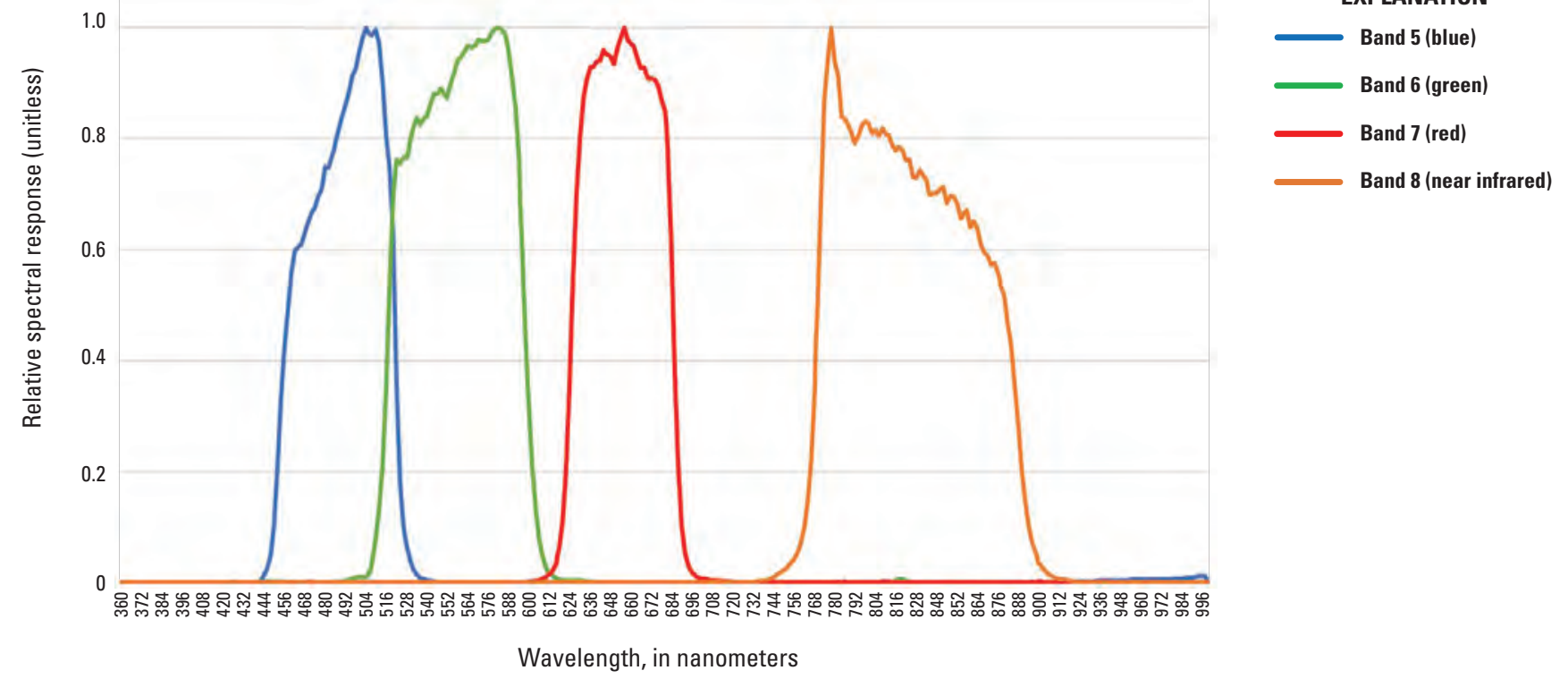

Figure 1. China-Brazil Earth Resources Satellite-4A multispectral camera sensor relative spectral response. 
Table 3. U.S. Geological Survey measurement results for China-Brazil Earth Resources Satellite-4A (CBERS-4A).

[USGS, U.S. Geological Survey; m, meter; SDDEV, standard deviation; RMSE, root mean square error; L8, Landsat 8; OLI, Operational Land Imager; RER, relative edge response; FWHM, full width at half maximum; MTF, modulation transfer function; NIR, near infrared]

\begin{tabular}{|c|c|}
\hline Description of product & Top of Atmosphere reflectance \\
\hline \multicolumn{2}{|r|}{ USGS measurement results } \\
\hline \multicolumn{2}{|c|}{ Geometric performance (easting, northing), in meters (pixels) } \\
\hline Exterior (geometric location accuracy) & $\begin{array}{l}\text { Mean: }-22.02 \mathrm{~m}(-1.47),-16.06 \mathrm{~m}(-1.07) \\
\text { SDDEV: } 3.40 \mathrm{~m}(0.23), 2.73 \mathrm{~m}(0.18) \\
\text { RMSE: } 22.35 \mathrm{~m}(1.49), 16.30 \mathrm{~m}(1.09)\end{array}$ \\
\hline \multicolumn{2}{|r|}{ Radiometric performance (offset, slope) } \\
\hline $\begin{array}{l}\text { Radiometric evaluation (linear regression- } \\
\text { CBERS-4A versus L8 OLI reflectance) }\end{array}$ & $\begin{array}{l}\text { Band } 5 \text { (offset, slope): }-0.006,0.925 \\
\text { Band } 6 \text { (offset, slope): }-0.004,0.863 \\
\text { Band } 7 \text { (offset, slope): }-0.003,0.824 \\
\text { Band } 8 \text { (offset, slope): }-0.004,0.625\end{array}$ \\
\hline \multicolumn{2}{|r|}{ Spatial performance } \\
\hline
\end{tabular}




\section{Analysis}

This section describes the geometric, radiometric, and spatial performance of the CBERS-4A satellite.

\section{Geometric Performance}

In this section, we describe the interior and exterior geometric performance of CBERS-4A. Interior accuracy measures how well the various bands of CBERS-4A are aligned to each other. Exterior accuracy measures the geometric location accuracy of CBERS-4A compared to Landsat imagery.

\section{Interior (Band to Band)}

The band-to-band alignment analysis was completed using the EROS System Characterization (EROSSC) software on three images over South America. Band combinations were registered against each other to determine the mean error and root mean square error, as shown in table 4, with results represented in pixels at a 15-m GSD (note that the CBERS data were resampled from 16 to $15 \mathrm{~m}$ for analysis with the $30-\mathrm{m}$ Landsat 8). Geometric error maps for each assessed band combination over the Belo Horizonte, Brazil, image, as well as the corresponding histogram graphs and error plots, are shown in figures $2-19$. The geometric error maps indicate the directional shift and relative magnitude of the shift, and the histogram graphs indicate the frequency of observed mean error measurements within the image. The geometric error plots indicate the easting and northing errors between the designated bands. Together, the interior and exterior geometric analysis results, as reported in the "Interior (Band to Band)" and "Exterior (Geometric Location Accuracy)" sections, provide a comprehensive assessment of geometric accuracy.

\section{Exterior (Geometric Location Accuracy)}

For this analysis, band 6 (green) of the CBERS-4A data was compared against the corresponding band from three Landsat 8 OLI images over sites in Brazil and Peru using the EROSSC software. Conjugate points in the reference and search images were identified automatically and refined using similarity measures such as normalized cross-correlation metrics. The mean error and root mean square error results are listed in table 5 with results represented in pixels at a 15-m GSD. For each of the three images, geometric error maps showing the directional shift and relative magnitude of the shift, when compared with Landsat 8 OLI, along with the corresponding histogram graphs and error plots are provided in figures 20-28. The Landsat 8 OLI imagery had a control uncertainty of about $8 \mathrm{~m}$.

Table 4. Band-to-band registration error (in pixels).

[ID, identifier; SDDEV, standard deviation; RMSE, root mean square error; $\sim$, about; \%, percent]

\begin{tabular}{|c|c|c|c|c|c|c|c|}
\hline Scene ID & Band combination & $\begin{array}{l}\text { Mean error } \\
\text { (easting) }\end{array}$ & $\begin{array}{l}\text { Mean error } \\
\text { (northing) }\end{array}$ & $\begin{array}{c}\text { SDDEV } \\
\text { error } \\
\text { (easting) }\end{array}$ & $\begin{array}{c}\text { SDDEV } \\
\text { error } \\
\text { (northing) }\end{array}$ & $\begin{array}{c}\text { RMSE } \\
\text { error } \\
\text { (easting) }\end{array}$ & $\begin{array}{c}\text { RMSE } \\
\text { error } \\
\text { (northing) }\end{array}$ \\
\hline \multirow{5}{*}{$\begin{array}{l}\text { CBERS_4A_ } \\
\text { MUX_20200913_200_138_L4 } \\
\text { (Belo_Horizonte, Brazil) }\end{array}$} & Band 5-band 6 & -0.042 & 0.064 & 0.019 & 0.031 & 0.046 & 0.071 \\
\hline & Band 5-band 7 & -0.050 & -0.047 & 0.046 & 0.047 & 0.068 & 0.067 \\
\hline & Band 5-band 8 & -0.137 & -0.126 & 0.171 & 0.171 & 0.219 & 0.212 \\
\hline & Band 6-band 7 & -0.008 & -0.103 & 0.045 & 0.035 & 0.046 & 0.109 \\
\hline & Band 7-band 8 & -0.092 & -0.088 & 0.144 & 0.162 & 0.170 & 0.184 \\
\hline \multirow{3}{*}{$\begin{array}{l}\text { CBERS_4A_- } \\
\text { MUX_20200225_234_136_L4 } \\
\text { (Tacna, Peru) } \\
\text { Note: this image had } ~ 25 \% \\
\text { ocean and clouds. A mask was } \\
\text { applied so these areas were not } \\
\text { used for analysis. }\end{array}$} & Band 5-band 6 & -0.041 & 0.062 & 0.052 & 0.043 & 0.066 & 0.075 \\
\hline & Band 5-band 7 & -0.047 & -0.076 & 0.087 & 0.087 & 0.099 & 0.115 \\
\hline & Band 5-band 8 & -0.123 & -0.211 & 0.109 & 0.118 & 0.164 & 0.242 \\
\hline \multirow{6}{*}{$\begin{array}{l}\text { CBERS_4A_ } \\
\text { MUX_20200115_205_140_L4 } \\
\text { (Curitiba, Brazil) }\end{array}$} & Band 5-band 6 & -0.051 & 0.066 & 0.031 & 0.035 & 0.060 & 0.074 \\
\hline & Band 5-band 7 & -0.039 & -0.059 & 0.058 & 0.043 & 0.070 & 0.073 \\
\hline & Band 5-band 8 & 0.124 & -0.139 & 0.176 & 0.149 & 0.215 & 0.204 \\
\hline & Band 6-band 7 & 0.012 & -0.102 & 0.058 & 0.044 & 0.060 & 0.111 \\
\hline & Band 6-band 8 & 0.181 & -0.190 & 0.189 & 0.159 & 0.262 & 0.247 \\
\hline & Band 7-band 8 & 0.090 & -0.081 & 0.112 & 0.900 & 0.143 & 0.121 \\
\hline
\end{tabular}




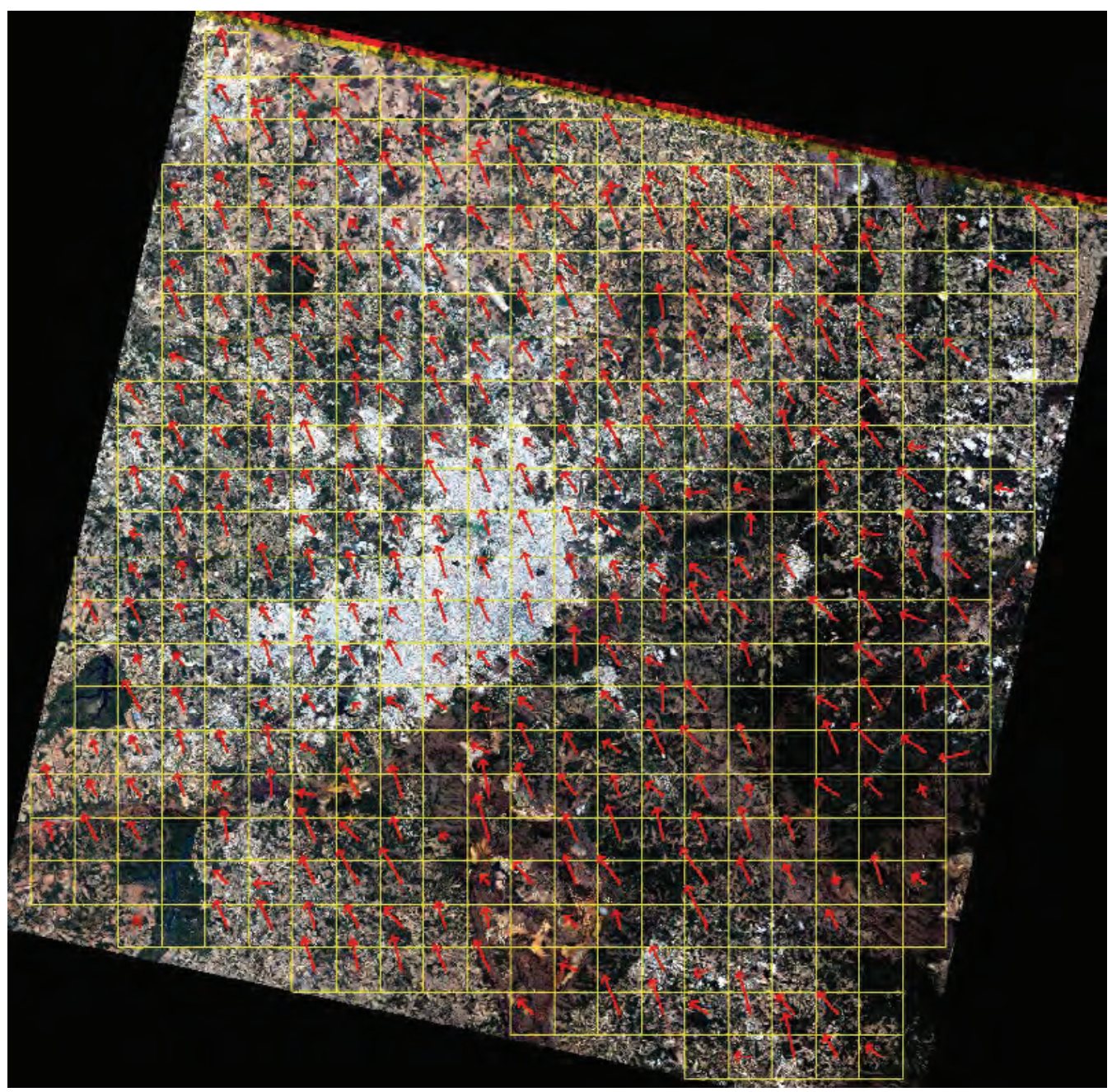

EXPLANATION

$\longrightarrow$ Easting and northing error - Grid

Figure 2. Band 5 (blue) to band 6 (green) geometric error map (Belo Horizonte, Brazil). 

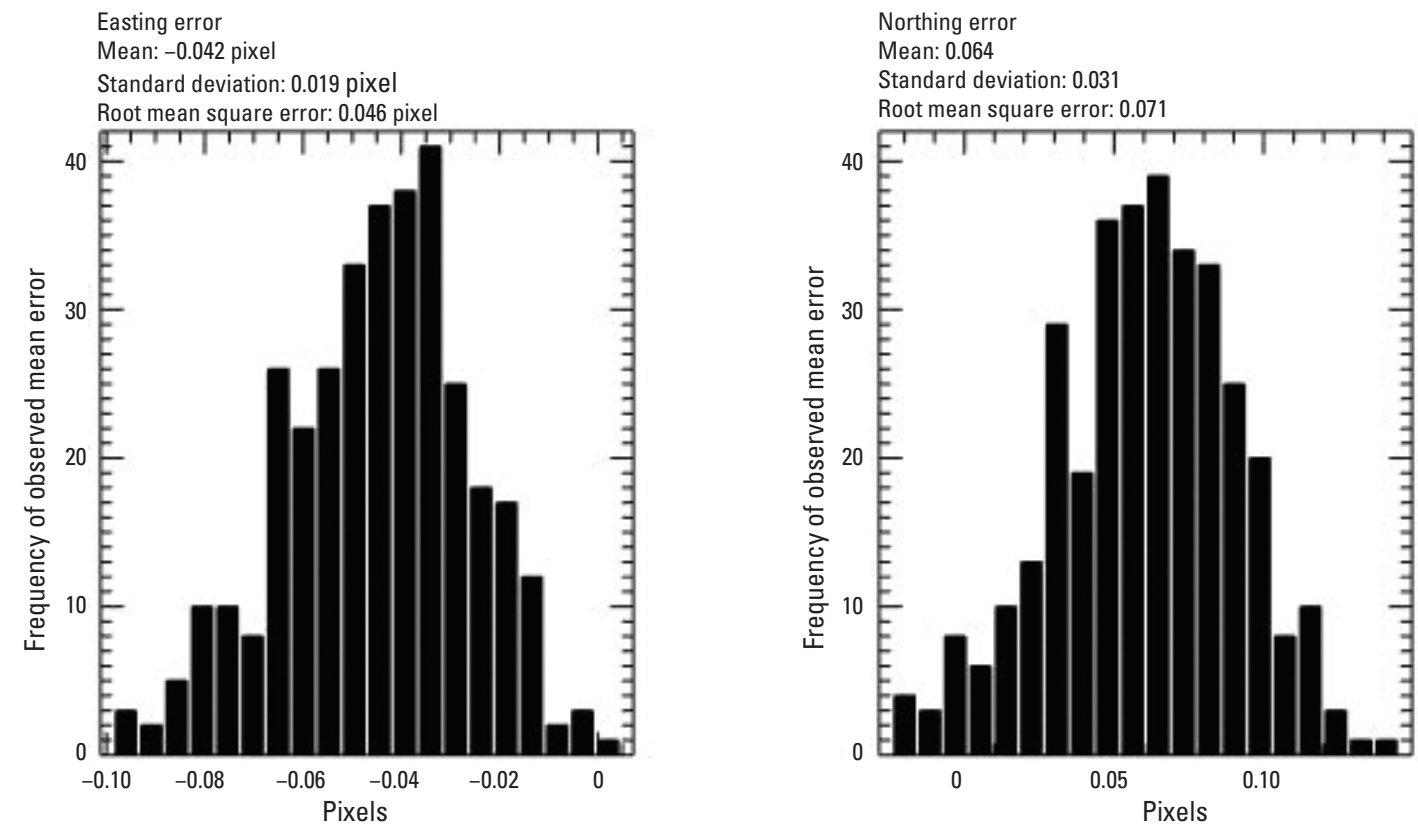

Figure 3. Band 5 (blue) to band 6 (green) geometric error histogram (Belo Horizonte, Brazil).

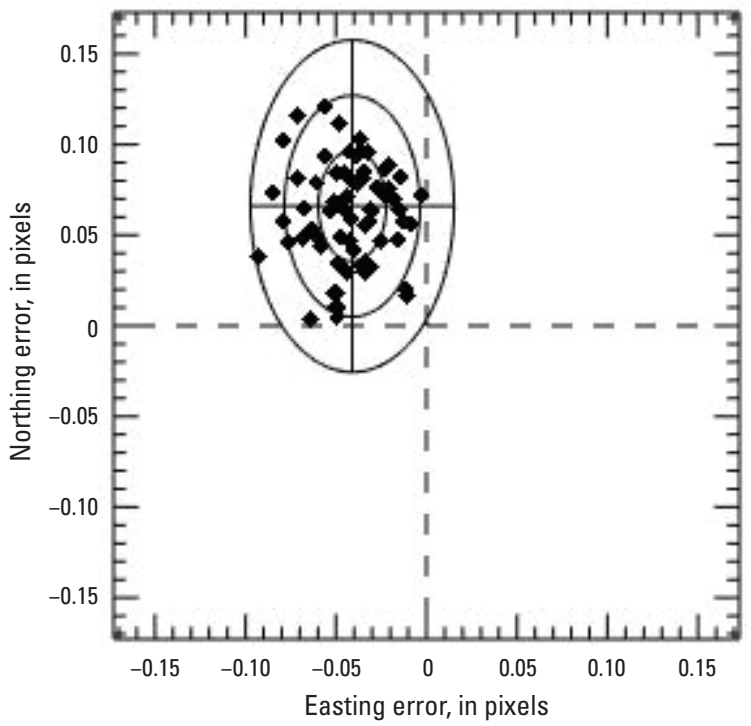

Figure 4. Band 5 (blue) to band 6 (green) geometric error plot (Belo Horizonte, Brazil). 


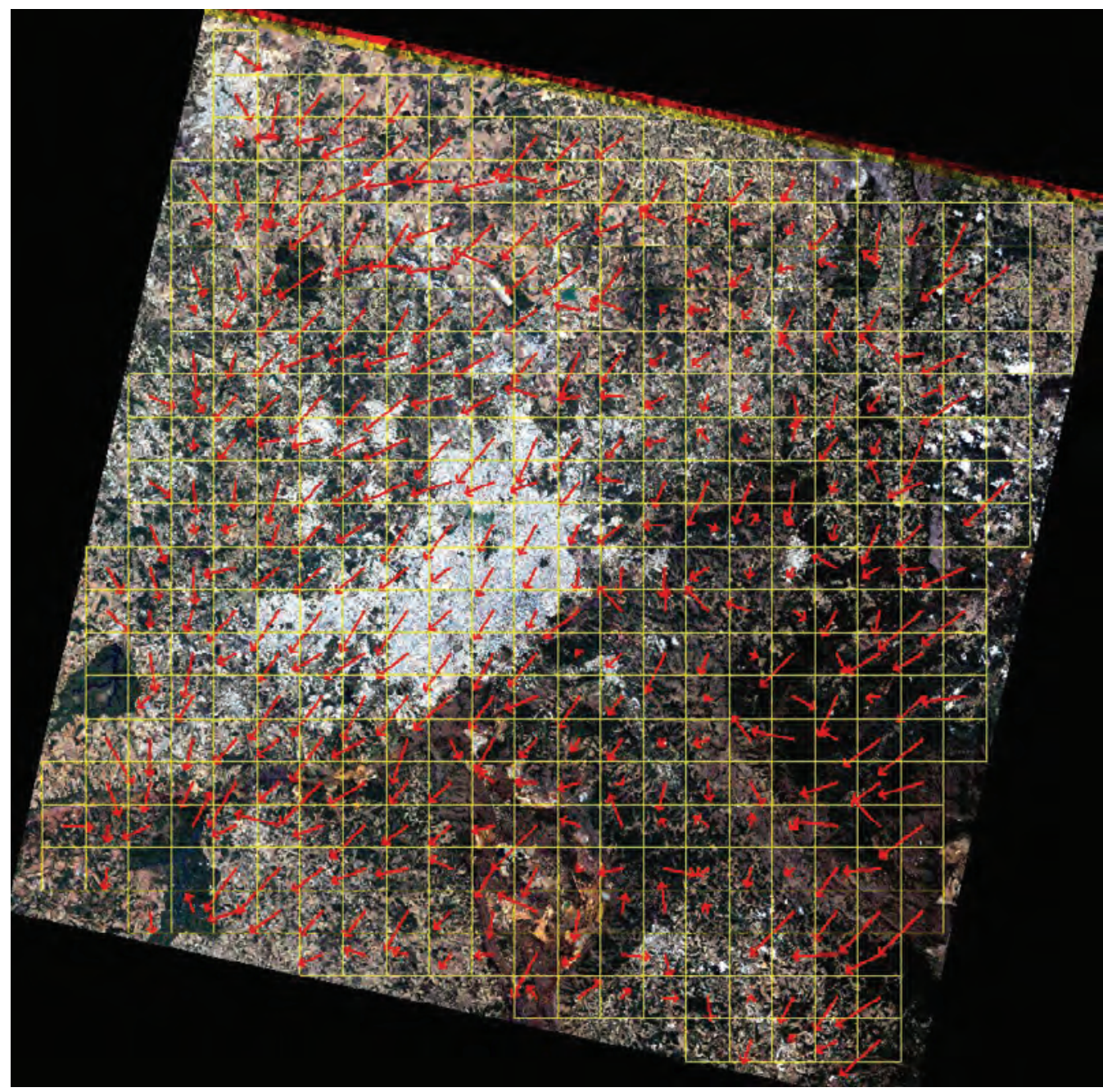

EXPLANATION

$\longrightarrow$ Easting and northing error Grid

Figure 5. Band 5 (blue) to band 7 (red) geometric error map (Belo Horizonte, Brazil). 

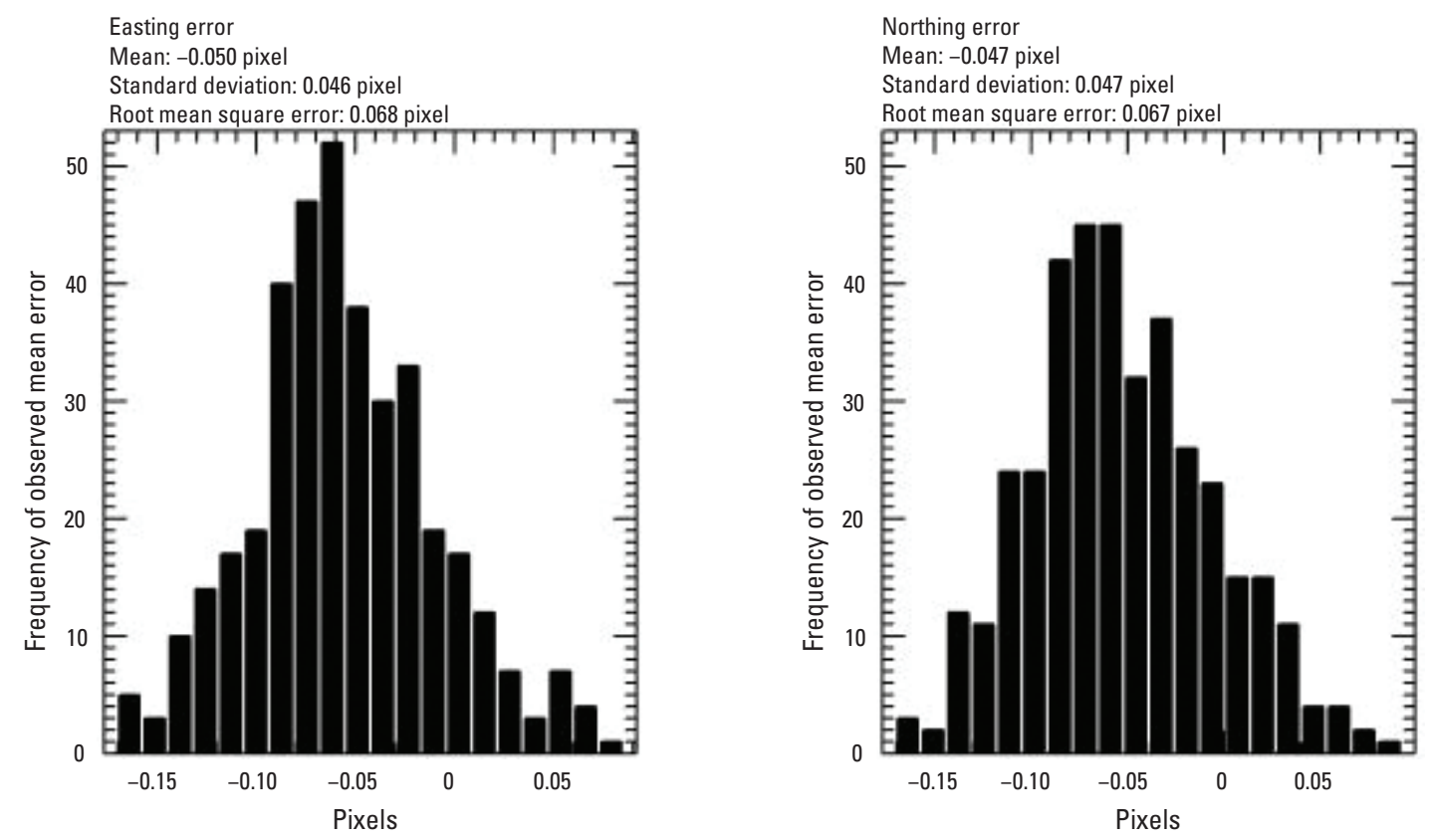

Figure 6. Band 5 (blue) to band 7 (red) geometric error histogram (Belo Horizonte, Brazil).

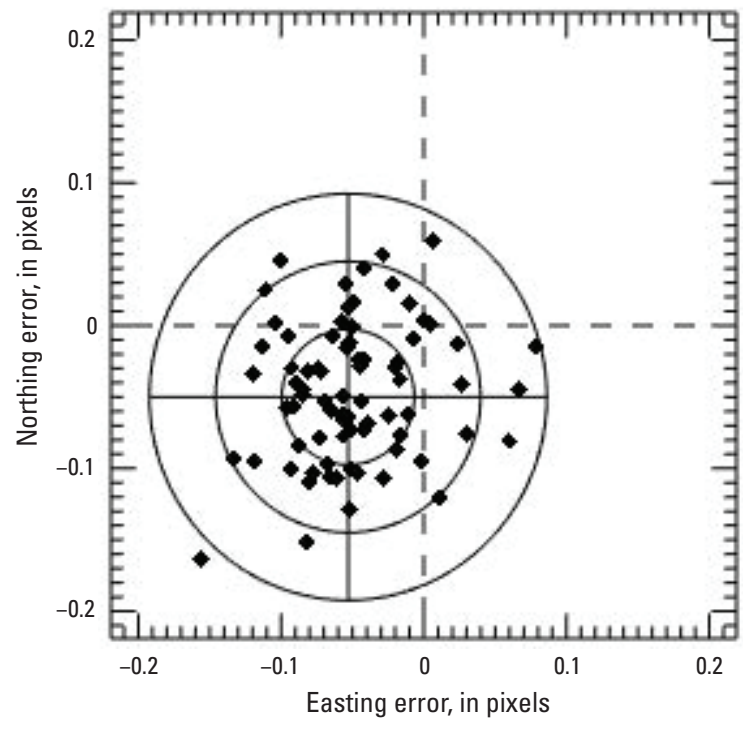

Figure 7. Band 5 (blue) to band 7 (red) geometric error plot (Belo Horizonte, Brazil). 


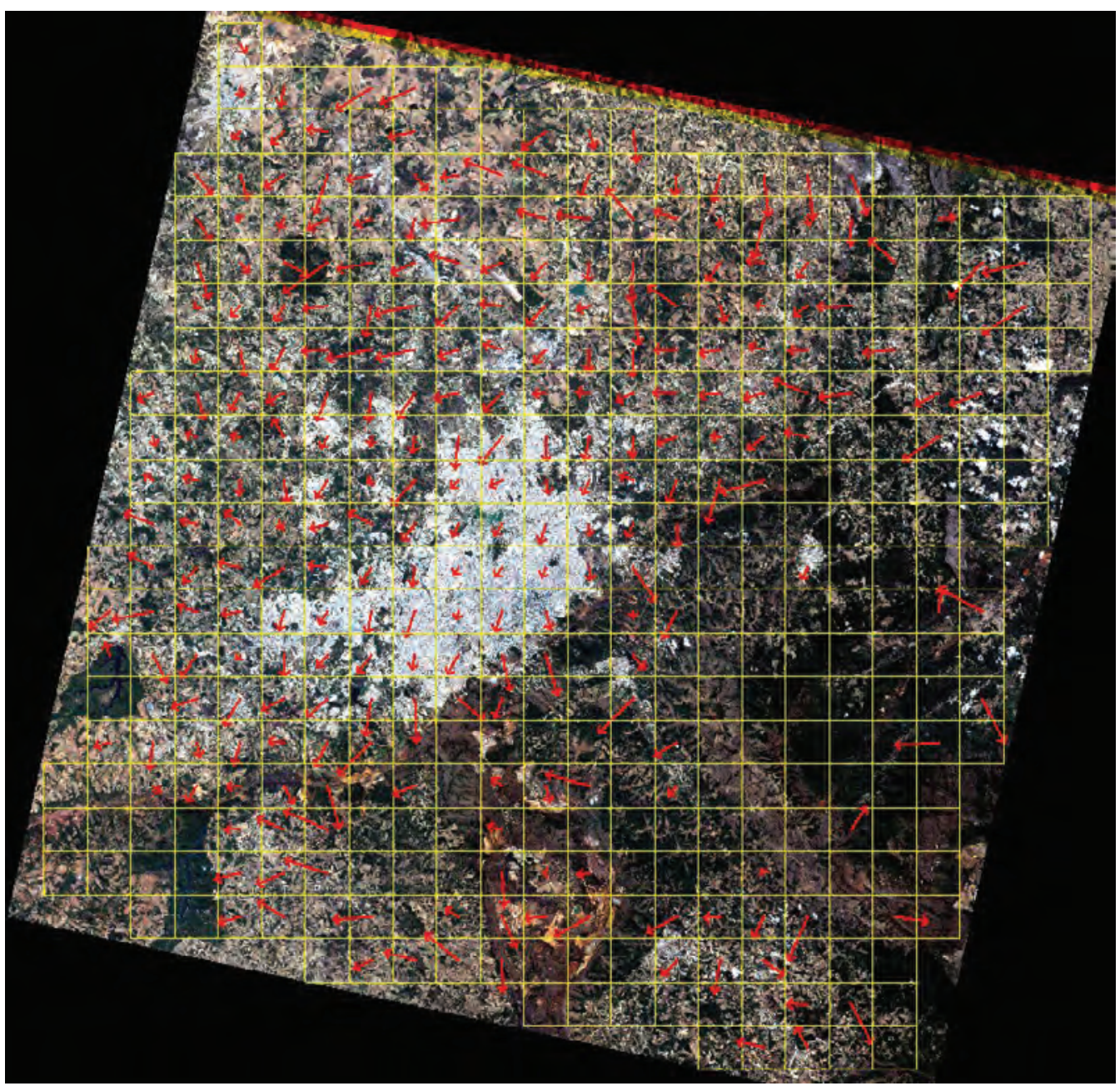

EXPLANATION

$\longrightarrow$ Easting and northing error - Grid

Figure 8. Band 5 (blue) to band 8 (near infrared) geometric error map (Belo Horizonte, Brazil). 

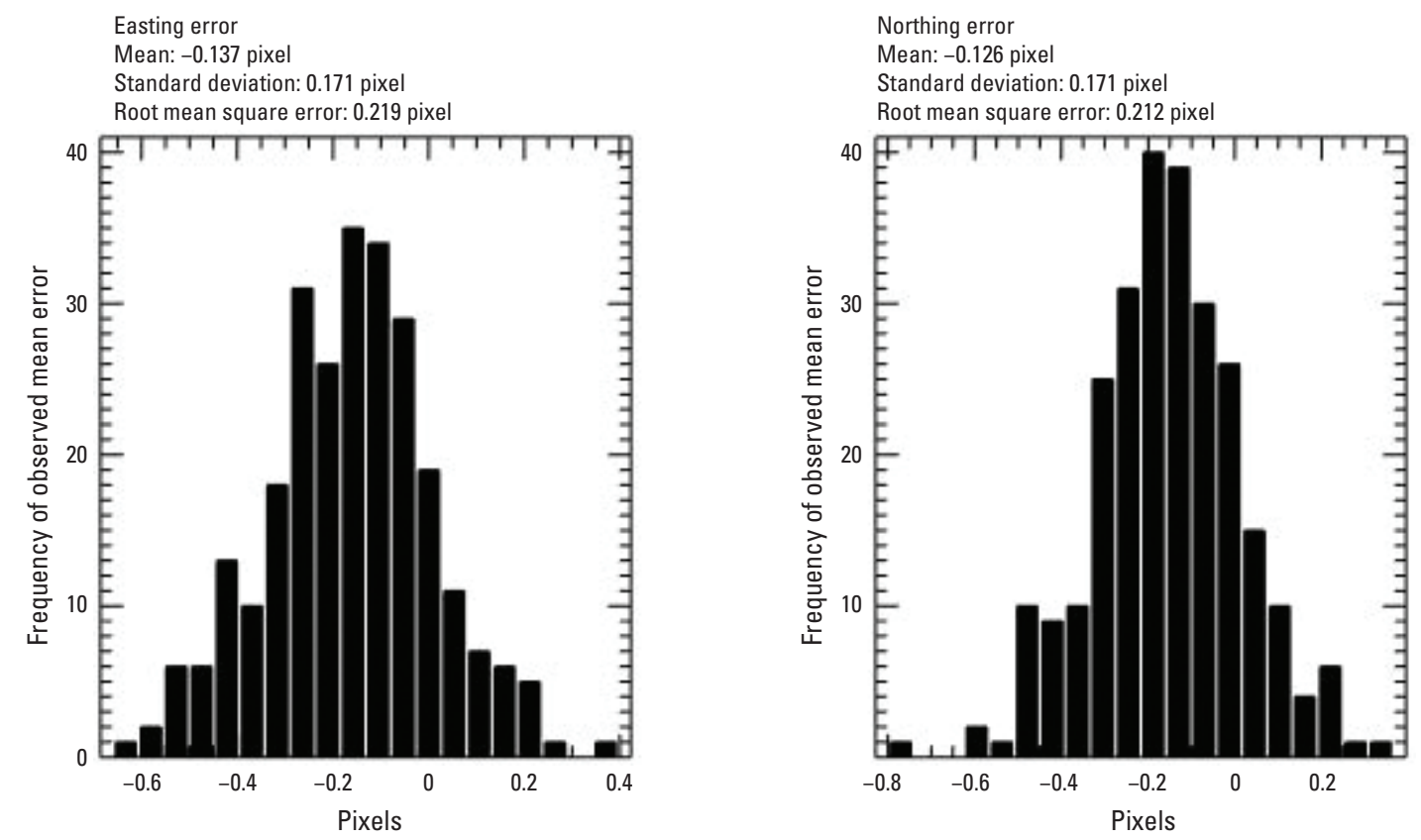

Figure 9. Band 5 (blue) to band 8 (near infrared) geometric error histogram (Belo Horizonte, Brazil).

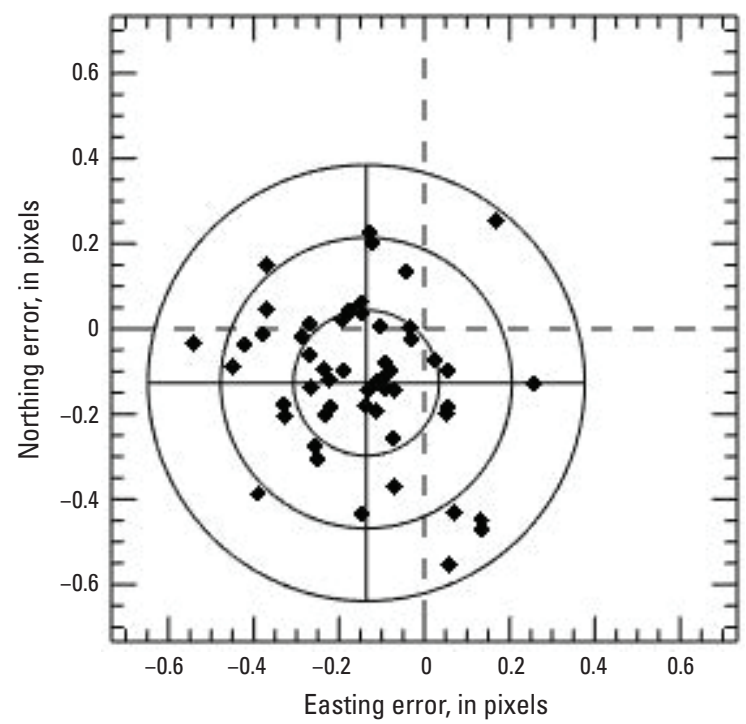

Figure 10. Band 5 (blue) to band 8 (near infrared) geometric error plot (Belo Horizonte, Brazil). 


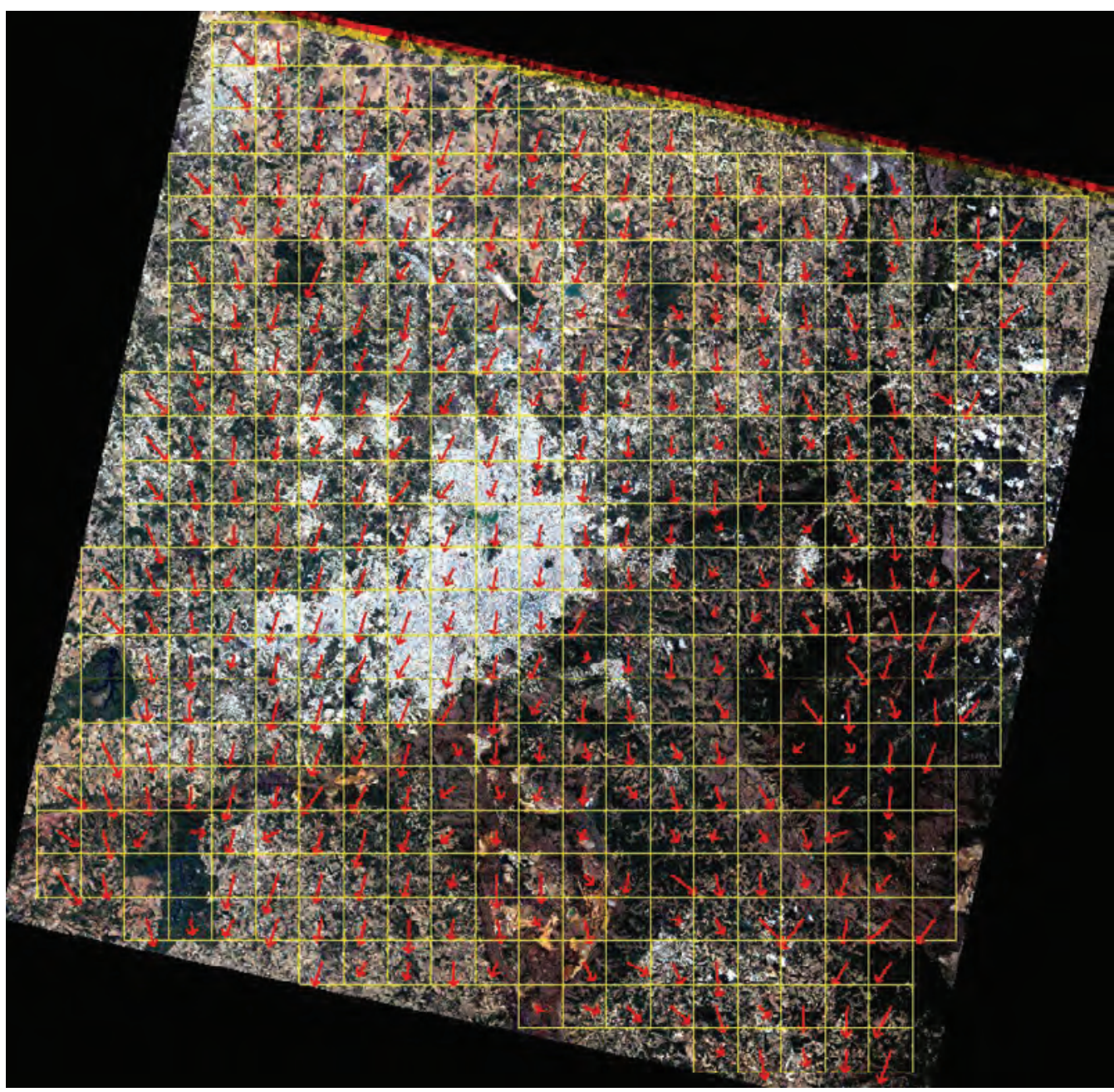

EXPLANATION

$\longrightarrow$ Easting and northing error Grid

Figure 11. Band 6 (green) to band 7 (red) geometric error map (Belo Horizonte, Brazil). 

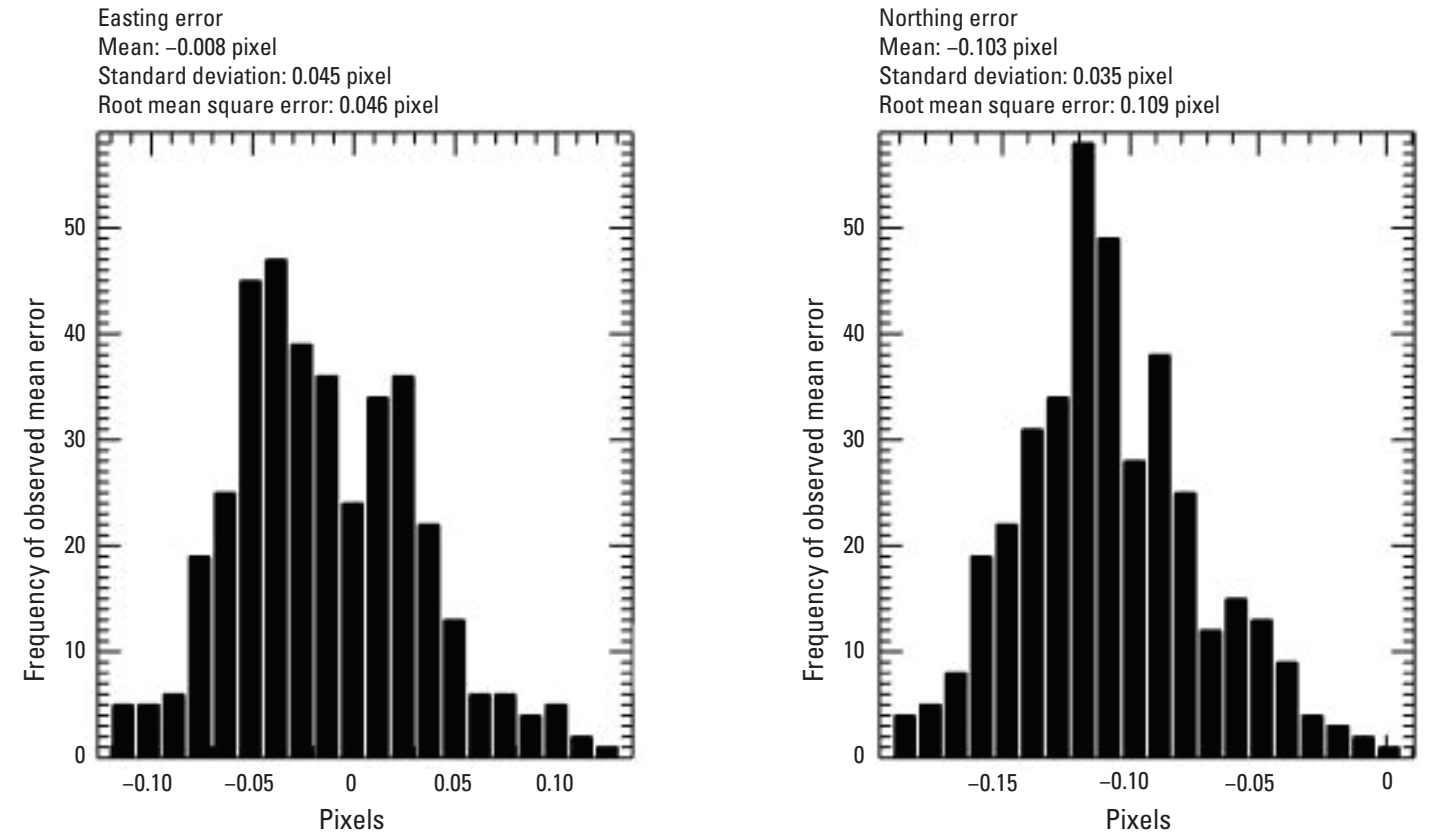

Figure 12. Band 6 (green) to band 7 (red) geometric error histogram (Belo Horizonte, Brazil).

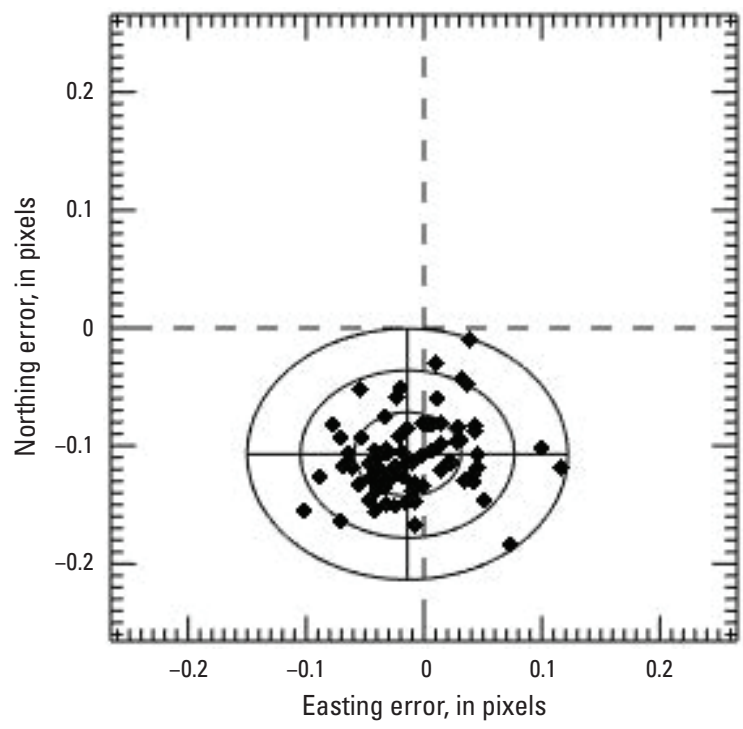

Figure 13. Band 6 (green) to band 7 (red) geometric error plot (Belo Horizonte, Brazil). 


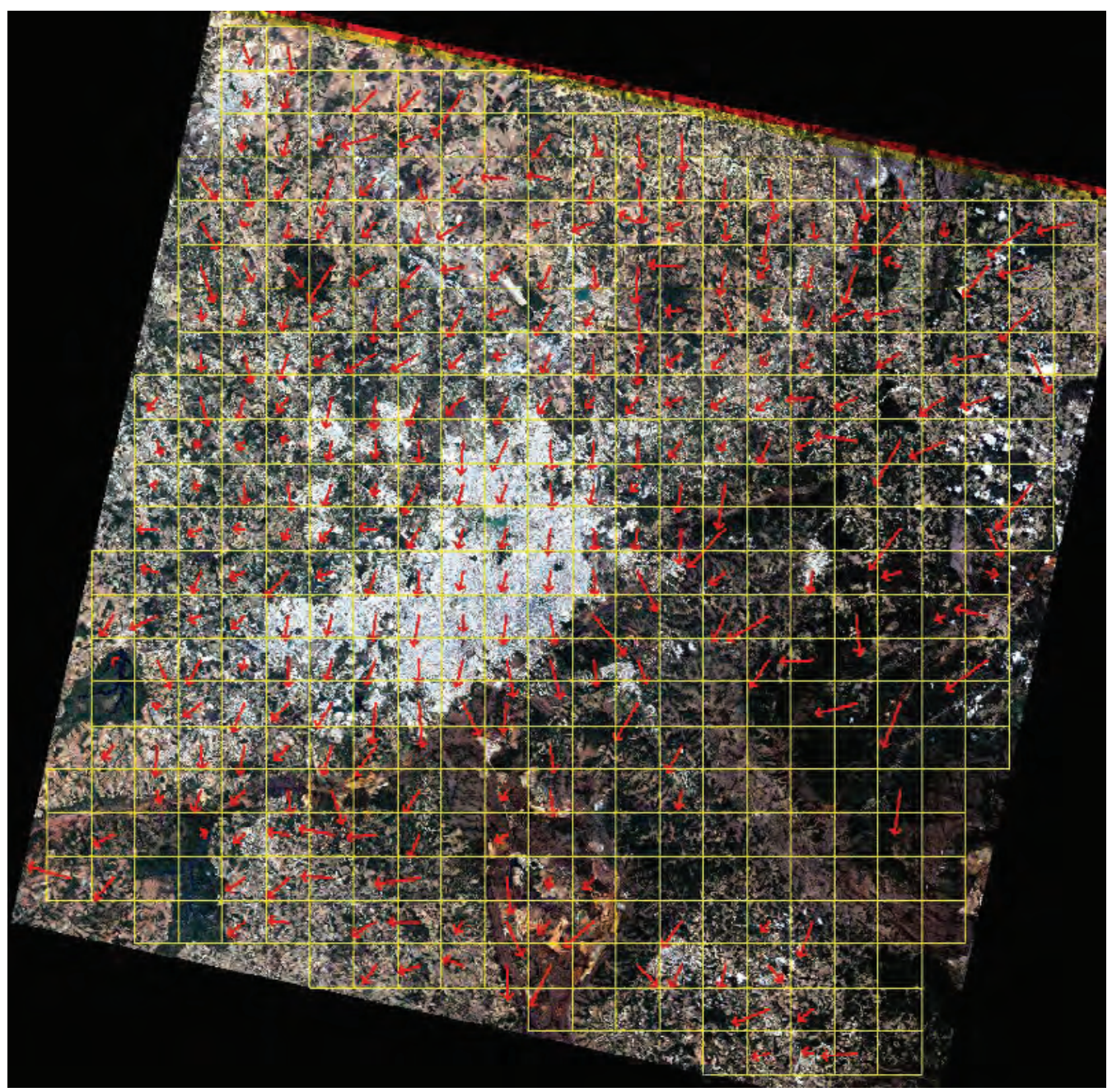

\section{EXPLANATION}

$\longrightarrow$ Easting and northing error Grid

Figure 14. Band 6 (green) to band 8 (near infrared) geometric error map (Belo Horizonte, Brazil). 

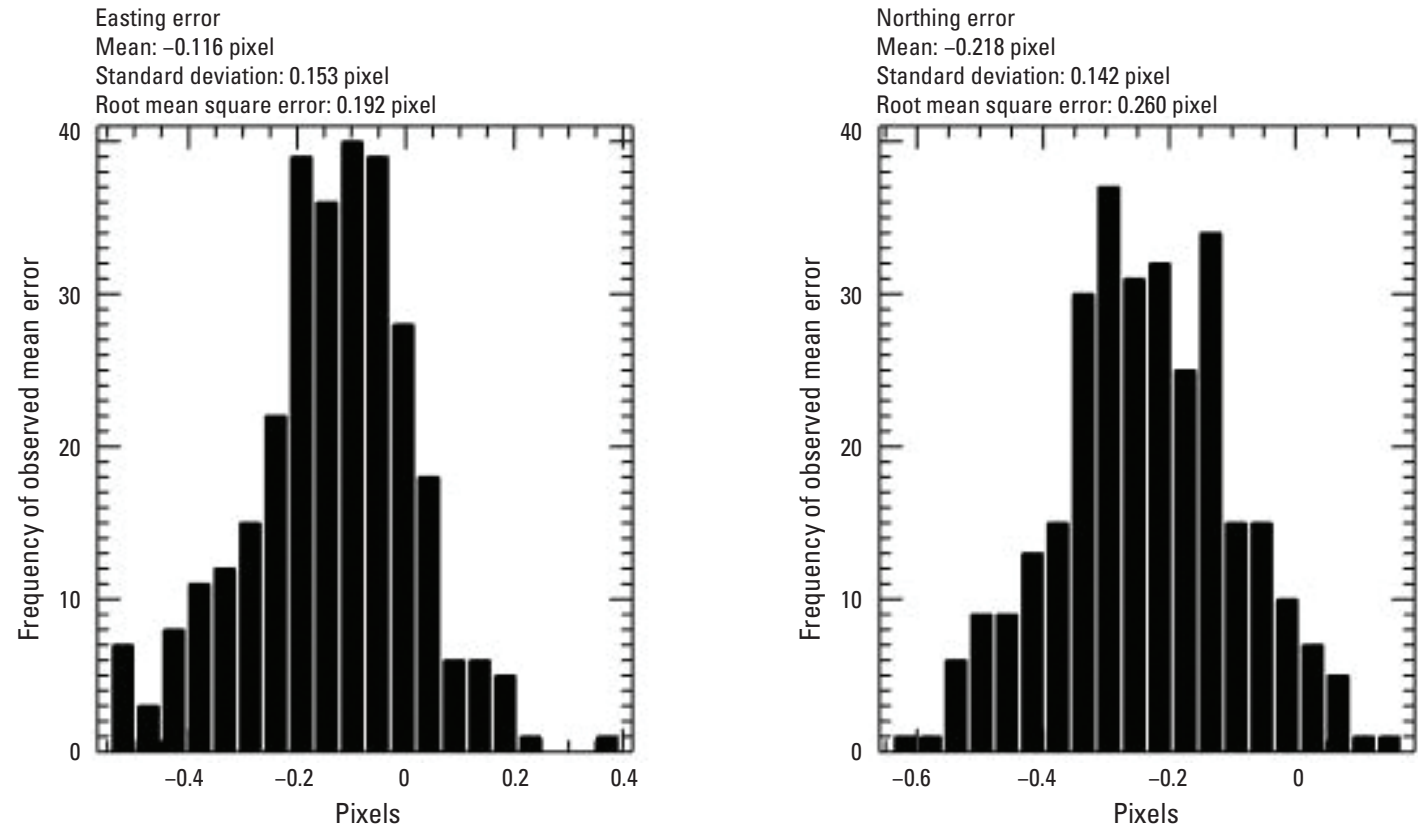

Figure 15. Band 6 (green) to band 8 (near infrared) geometric error histogram (Belo Horizonte, Brazil).

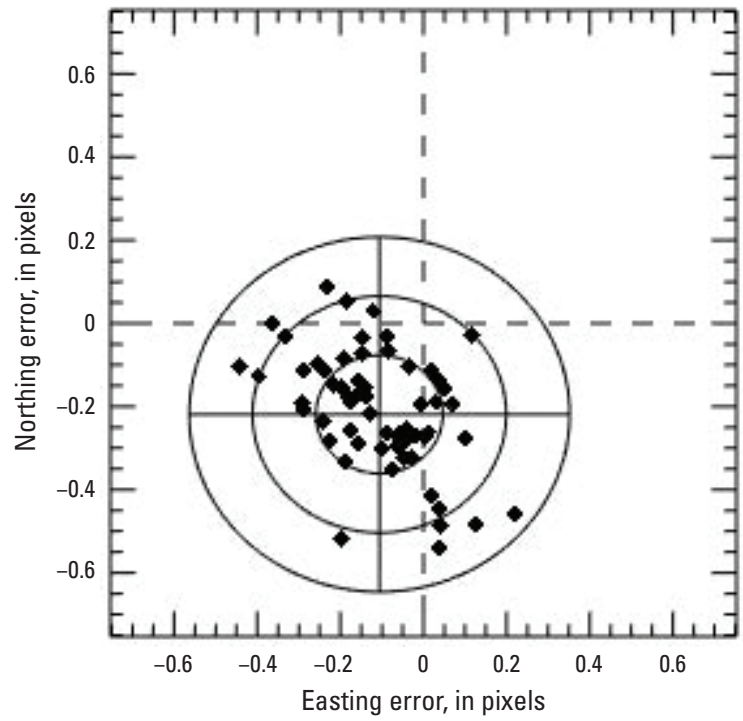

Figure 16. Band 6 (green) to band 8 (near infrared) geometric error plot (Belo Horizonte, Brazil). 


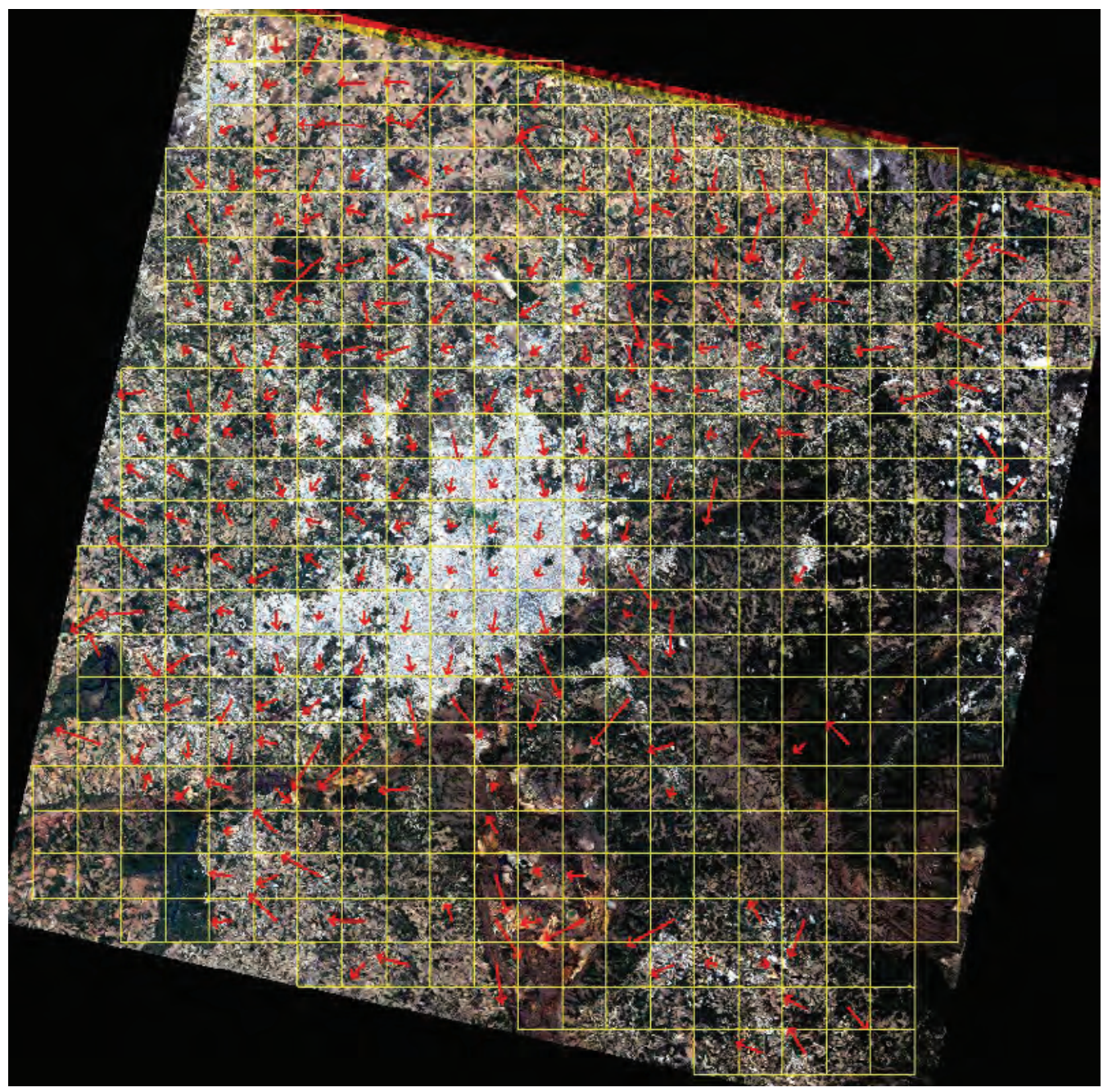

EXPLANATION

$\longrightarrow$ Easting and northing error Grid

Figure 17. Band 7 (red) to band 8 (near infrared) geometric error map (Belo Horizonte, Brazil). 

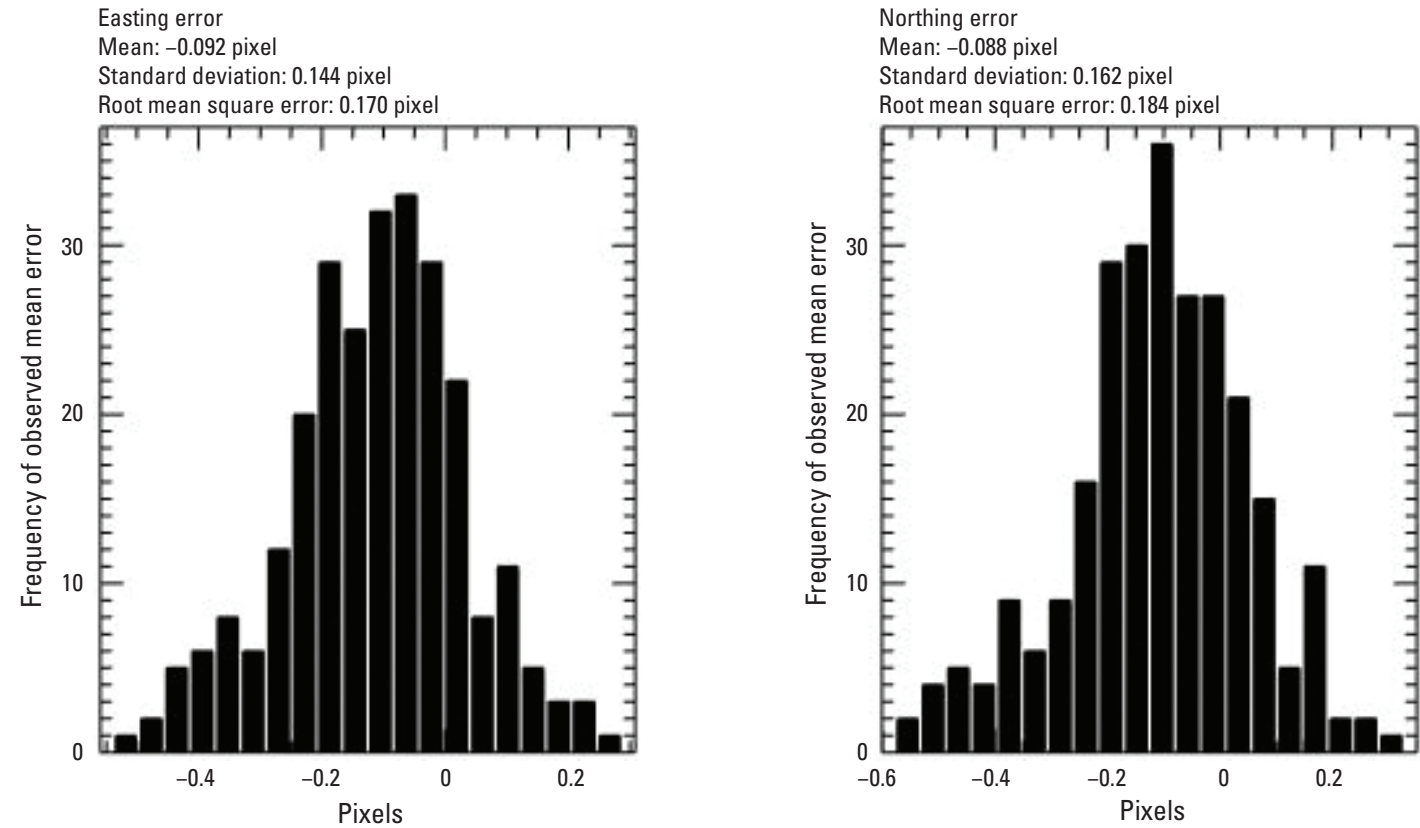

Figure 18. Band 7 (red) to band 8 (near infrared) geometric error histogram (Belo Horizonte, Brazil).

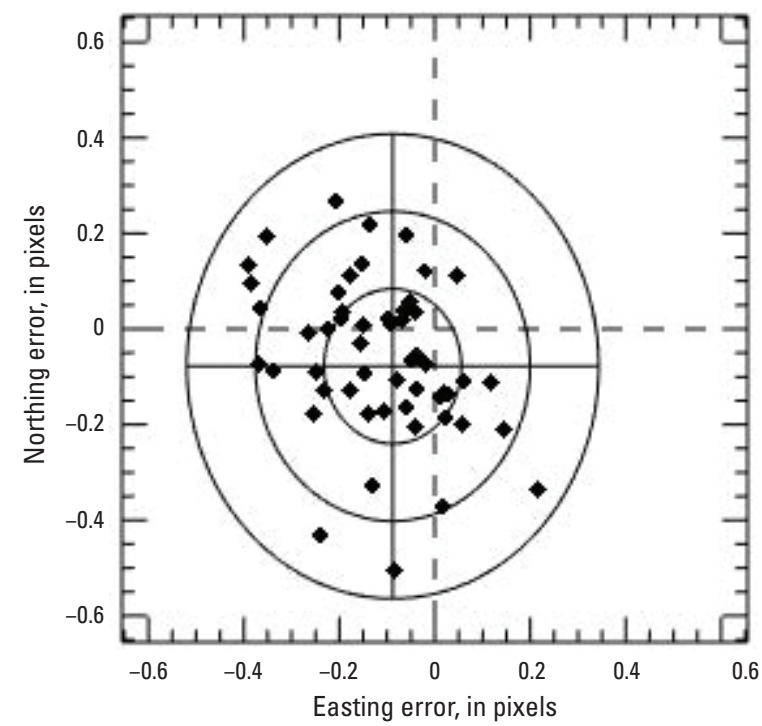

Figure 19. Band 7 (red) to band 8 (near infrared) geometric error plot (Belo Horizonte, Brazil). 
Table 5. Geometric error of China-Brazil Earth Resources Satellite-4A relative to Landsat 8.

[ID, identifier; SDDEV, standard deviation; RMSE, root mean square error; m, meter; , about; \%, percent]

\begin{tabular}{lcccccc}
\hline \multicolumn{1}{c}{ Scene ID } & $\begin{array}{c}\text { Mean error } \\
\text { (easting) }\end{array}$ & $\begin{array}{c}\text { Mean error } \\
\text { (northing) }\end{array}$ & $\begin{array}{c}\text { SDDEV error } \\
\text { (easting) }\end{array}$ & $\begin{array}{c}\text { SDDEV error } \\
\text { (northing) }\end{array}$ & $\begin{array}{c}\text { RMSE error } \\
\text { (easting) }\end{array}$ & $\begin{array}{c}\text { RMSE error } \\
\text { (northing) }\end{array}$ \\
\hline CBERS_4A_MUX_20200913_200_ & -1.92 pixels & -0.91 pixel & 0.22 pixel & 0.21 pixel & 1.94 pixels & 0.94 pixel \\
138_L4LC08_L1TP_218074_202009 & $(-28.848 \mathrm{~m})$ & $(-13.679 \mathrm{~m})$ & $(3.311 \mathrm{~m})$ & $(3.112 \mathrm{~m})$ & $(29.036 \mathrm{~m})$ & $(14.027 \mathrm{~m})$ \\
13_20200919_02_T1 & & & & & & \\
(Belo Horizonte, Brazil) & & & & & & \\
CBERS_4A_MUX_20200225_234_- & -1.71 pixels & -0.87 pixel & 0.20 pixel & 0.17 pixel & 1.72 pixels & 0.88 pixel \\
136_L4LC08_L1TP_002073_202002 & $(-25.621 \mathrm{~m})$ & $(-13.027 \mathrm{~m})$ & $(2.992 \mathrm{~m})$ & $(2.514 \mathrm{~m})$ & $(25.794 \mathrm{~m})$ & $(13.265 \mathrm{~m})$ \\
25_20200822_02_T1 (Tacna, Peru) & & & & & & \\
Note: this image had 25\% ocean and \\
clouds. A mask was applied so these
\end{tabular}




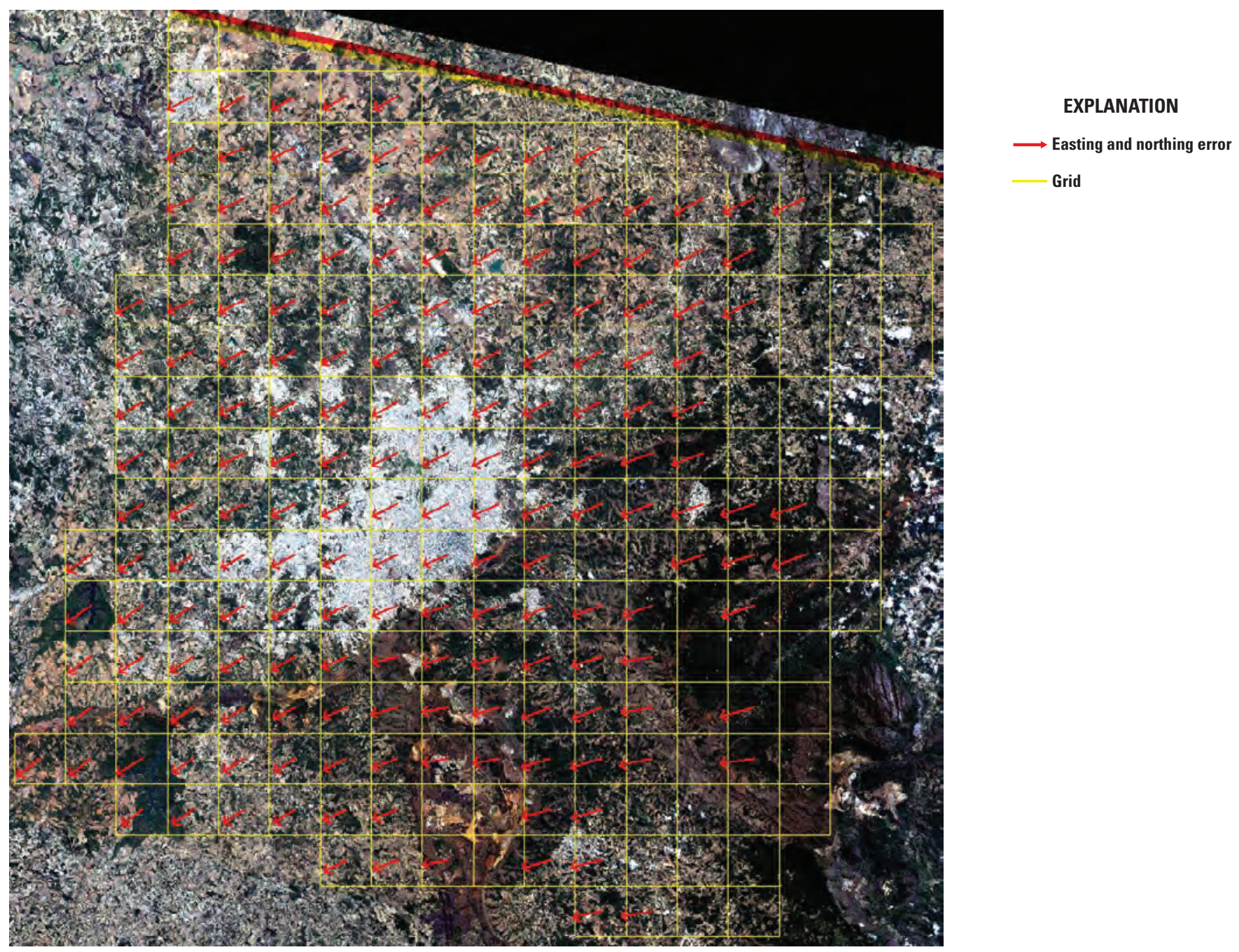

Figure 20. Relative geometric error comparison for Landsat 8 Operational Land Imager and China-Brazil Earth Resources Satellite-4A (Belo Horizonte, Brazil). 

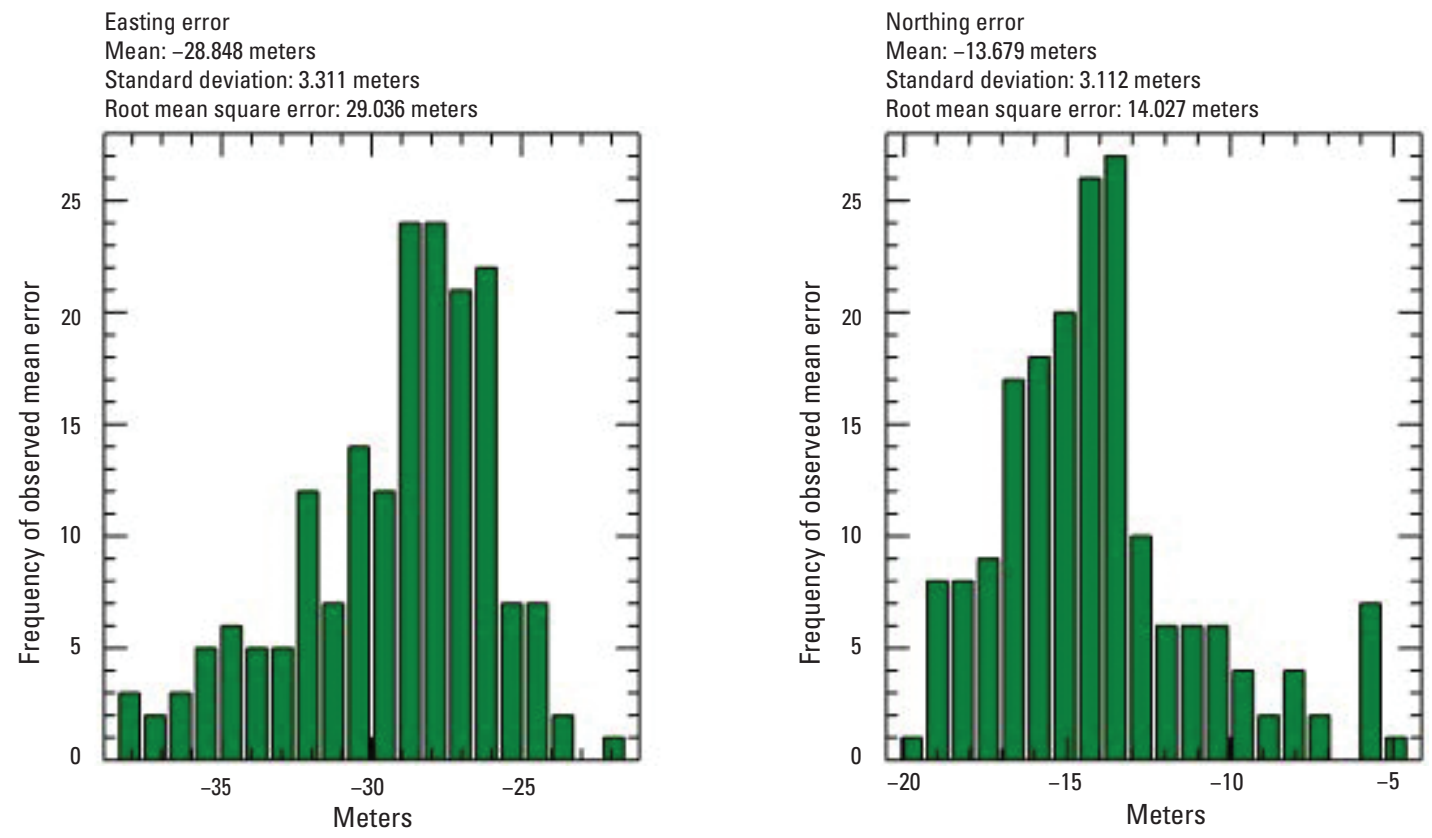

Figure 21. Relative geometric easting and northing error histogram comparison for Landsat 8 Operational Land Imager and China-Brazil Earth Resources Satellite-4A (Belo Horizonte, Brazil).

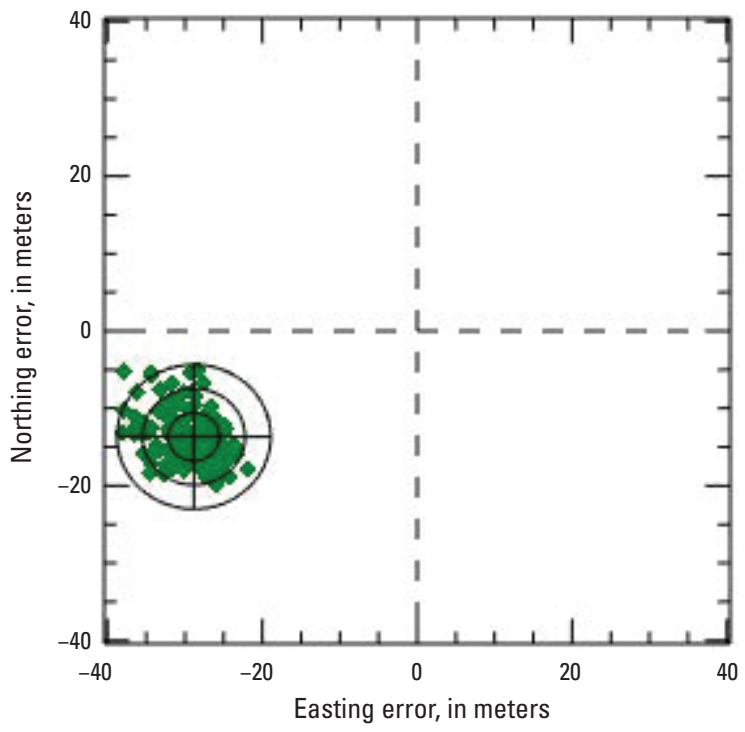

Figure 22. Relative geometric easting and northing error plot comparison for Landsat 8 Operational Land Imager and China-Brazil Earth Resources Satellite-4A (Belo Horizonte, Brazil). 


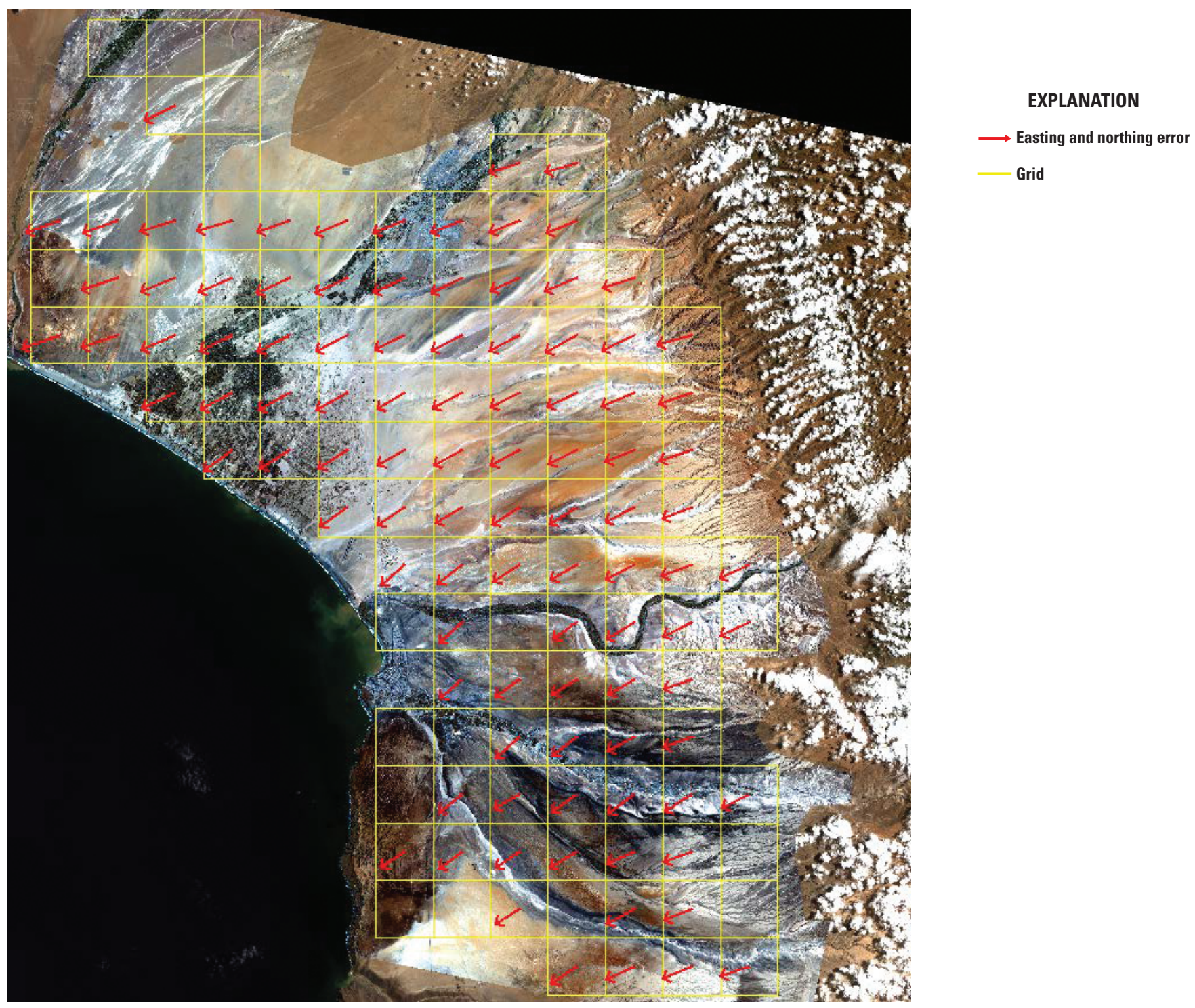

Figure 23. Relative geometric error comparison for Landsat 8 and China-Brazil Earth Resources Satellite-4A (Tacna, Peru). 

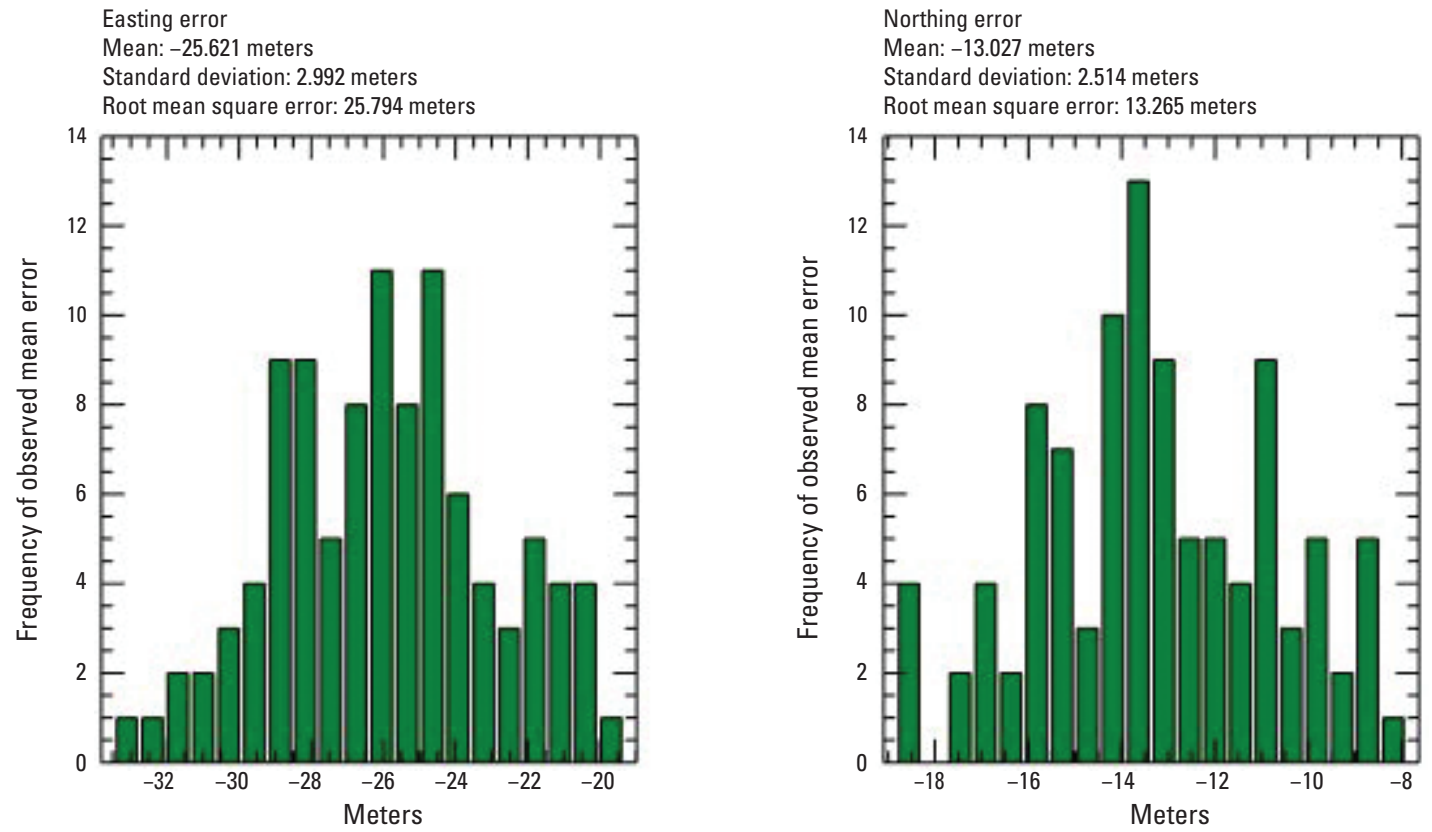

Figure 24. Relative geometric easting and northing error histogram comparison for Landsat 8 Operational Land Imager and China-Brazil Earth Resources Satellite-4A (Tacna, Peru).

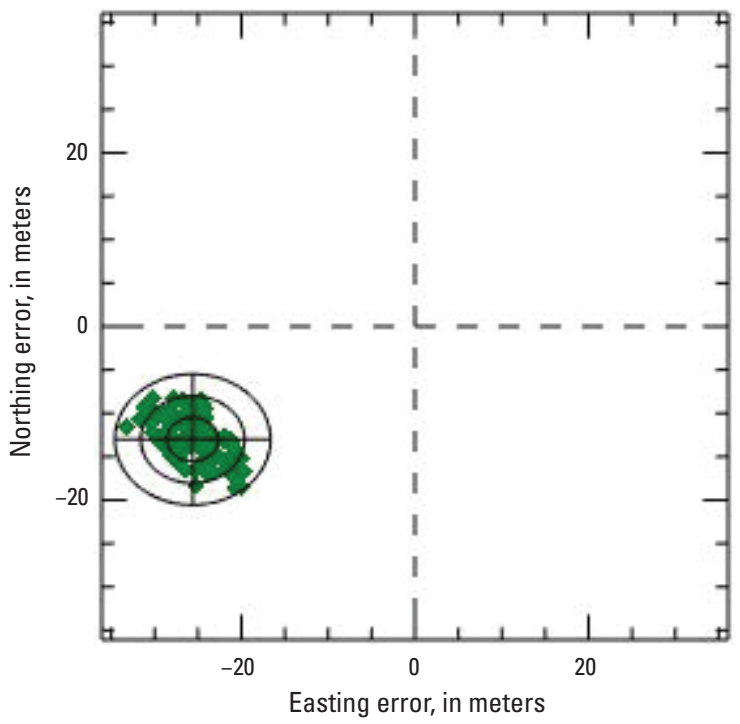

Figure 25. Relative geometric easting and northing error plot comparison for Landsat 8 Operational Land Imager and China-Brazil Earth Resources Satellite-4A (Tacna, Peru). 


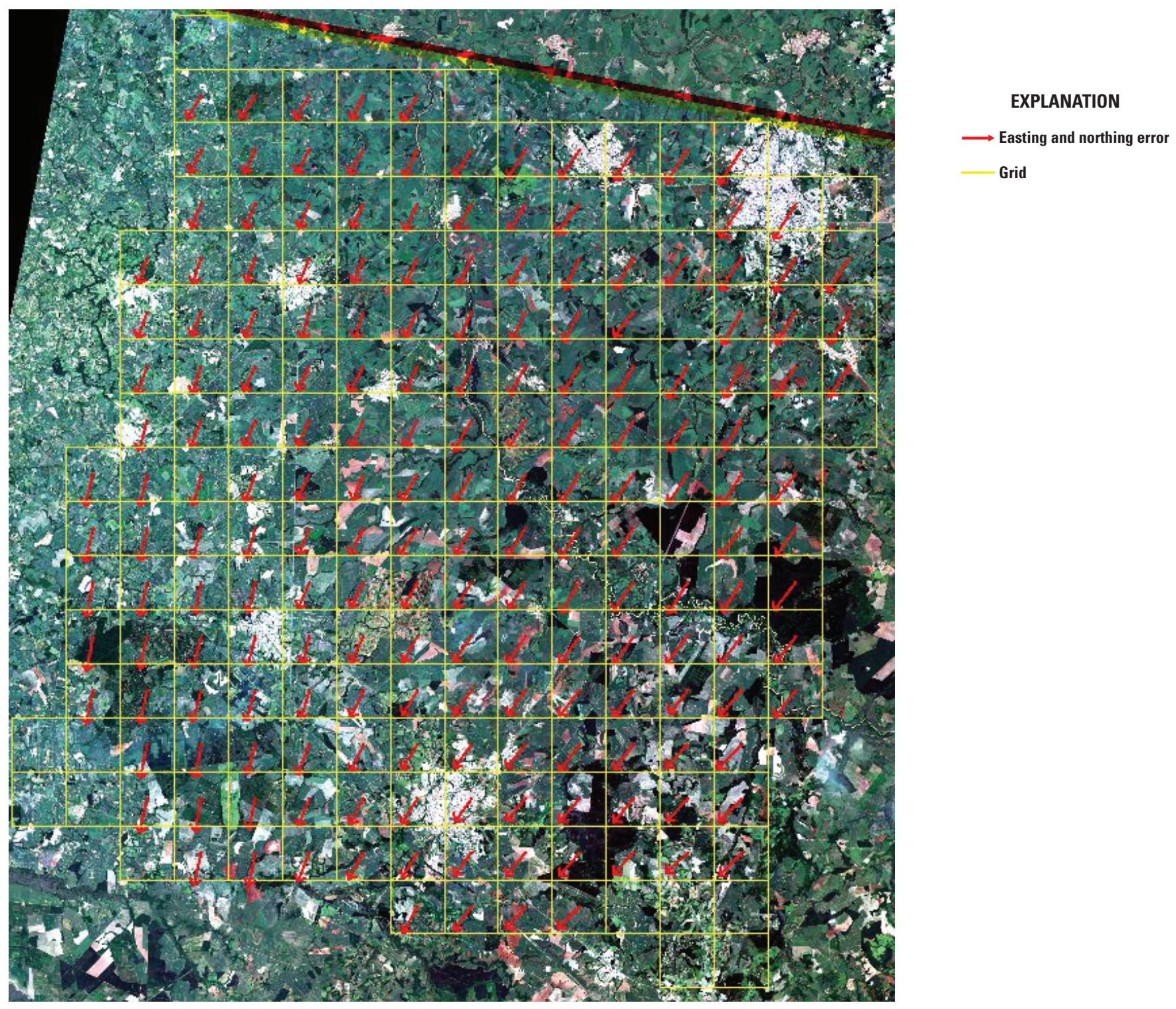

Figure 26. Relative geometric error comparison for Landsat 8 and China-Brazil Earth Resources Satellite-4A (Curitiba, Brazil). 

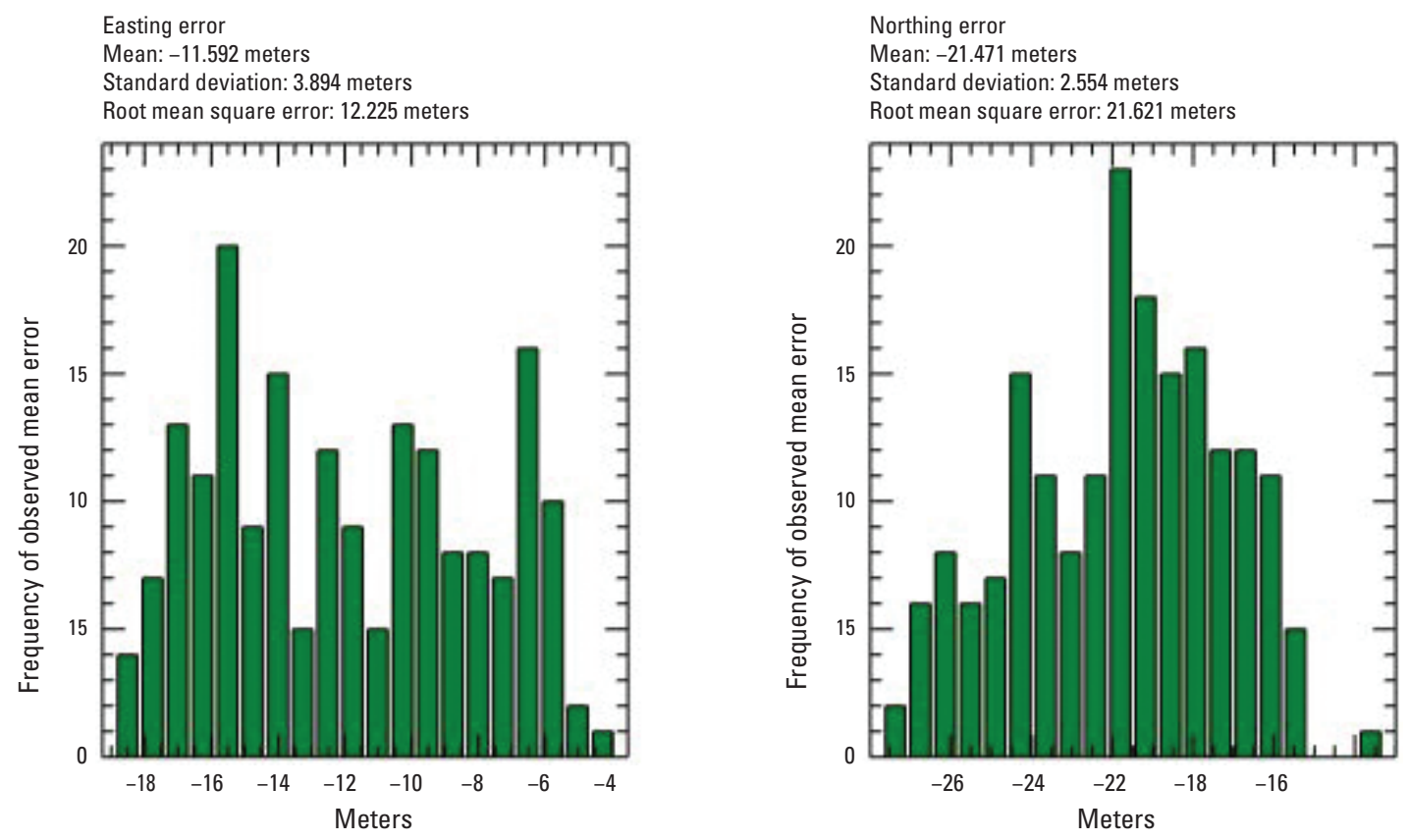

Figure 27. Relative geometric easting and northing error histogram comparison for Landsat 8 Operational Land Imager and China-Brazil Earth Resources Satellite-4A (Curitiba, Brazil).

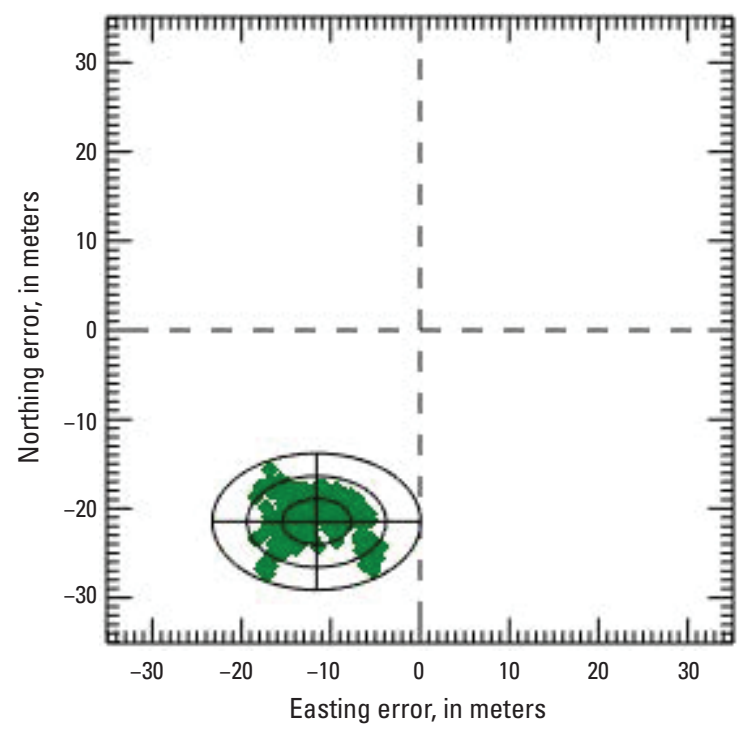

Figure 28. Relative geometric easting and northing error plot comparison for Landsat 8 Operational Land Imager and China-Brazil Earth Resources Satellite-4A (Curitiba, Brazil). 


\section{Radiometric Performance}

For this analysis, cloud-free regions of interest were selected within three near-coincident CBERS-4A and Landsat 8 OLI scene pairs using the EROSSC software. Once the relative georeferencing error between Landsat 8 OLI and CBERS-4A has been corrected, Top of Atmosphere reflectance values from the two sensors are extracted. The scatterplots (figs. 29-31) are drawn in a way that the x-axis is the reference sensor and the $y$-axis is the comparison sensor.
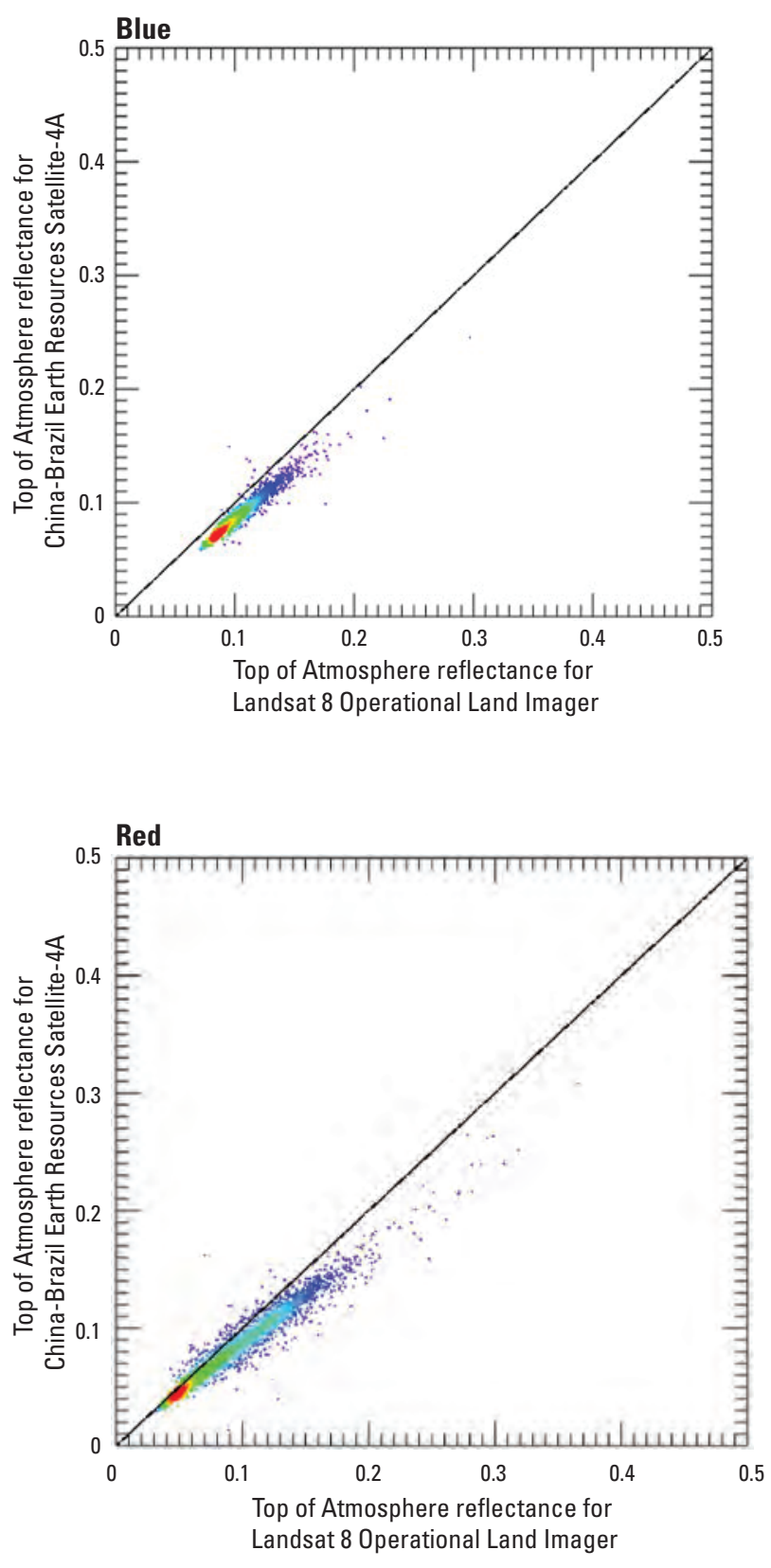

The linear regression, thus, represents Top of Atmosphere reflectance relative to that of the reference sensor. Ideally, the slope should be near unity, and the offset should be near zero. For instance, if the slope is greater than unity, that means the comparison sensor has a tendency to overestimate Top of Atmosphere reflectance compared to the reference sensor.

Top of Atmosphere reflectance comparison results are listed in table 6 . A band-by-band graphical comparison between the CBERS-4A image over Belo Horizonte, Brazil, when compared with the corresponding Landsat 8 OLI band is
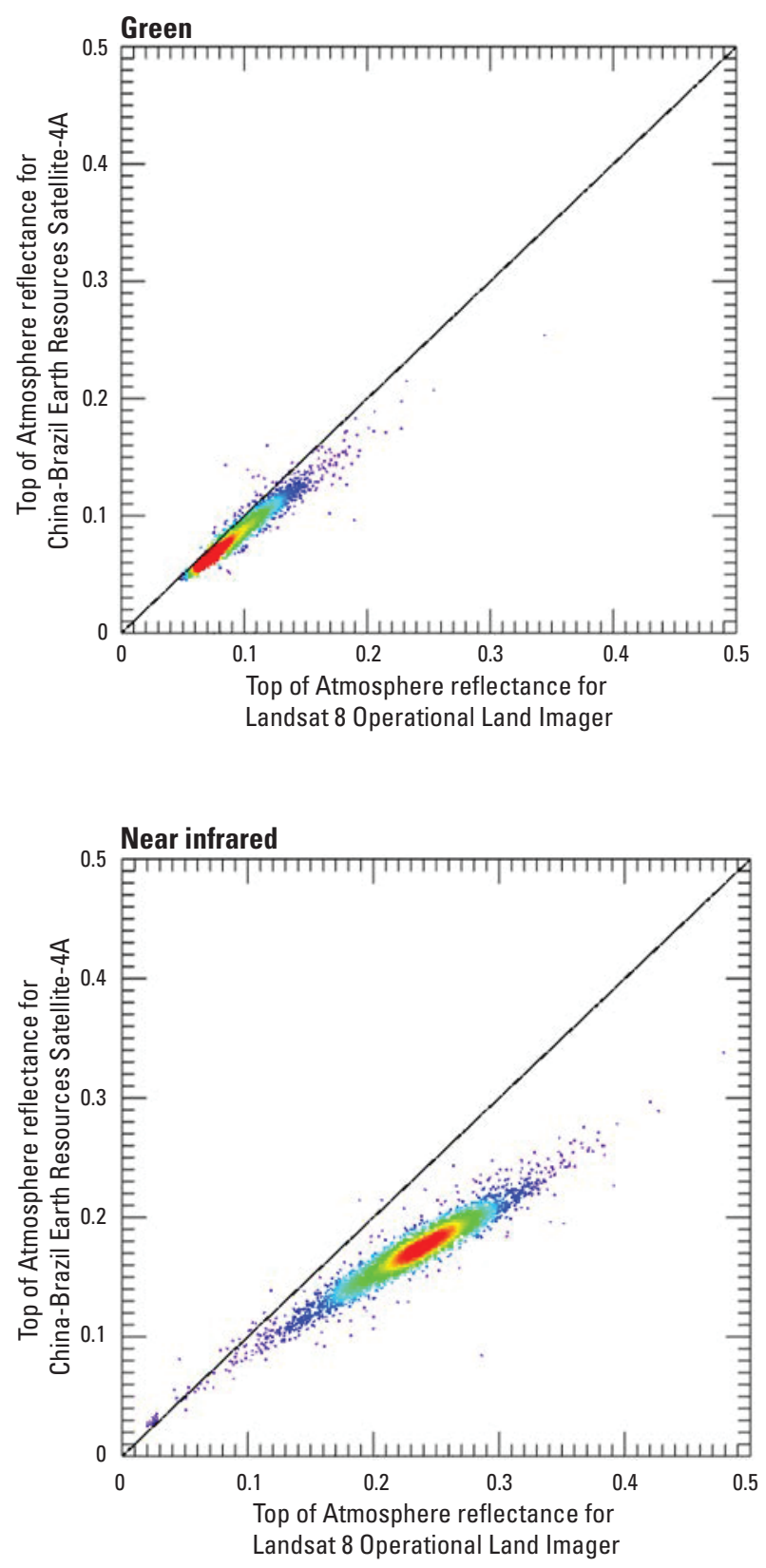

Figure 29. Top of Atmosphere reflectance comparison for Landsat 8 Operational Land Imager and China-Brazil Earth Resources Satellite-4A (Belo Horizonte, Brazil). 
shown in figure 29. A band-by-band comparison for the image over Tacna, Peru, is shown in figure 30, and a comparison over Curitiba, Brazil, is shown in figure 31 .

\section{Spatial Performance}

For this analysis, edge spread and line spread functions were calculated using the EROSSC software, with resulting relative edge response, full width at half maximum, and
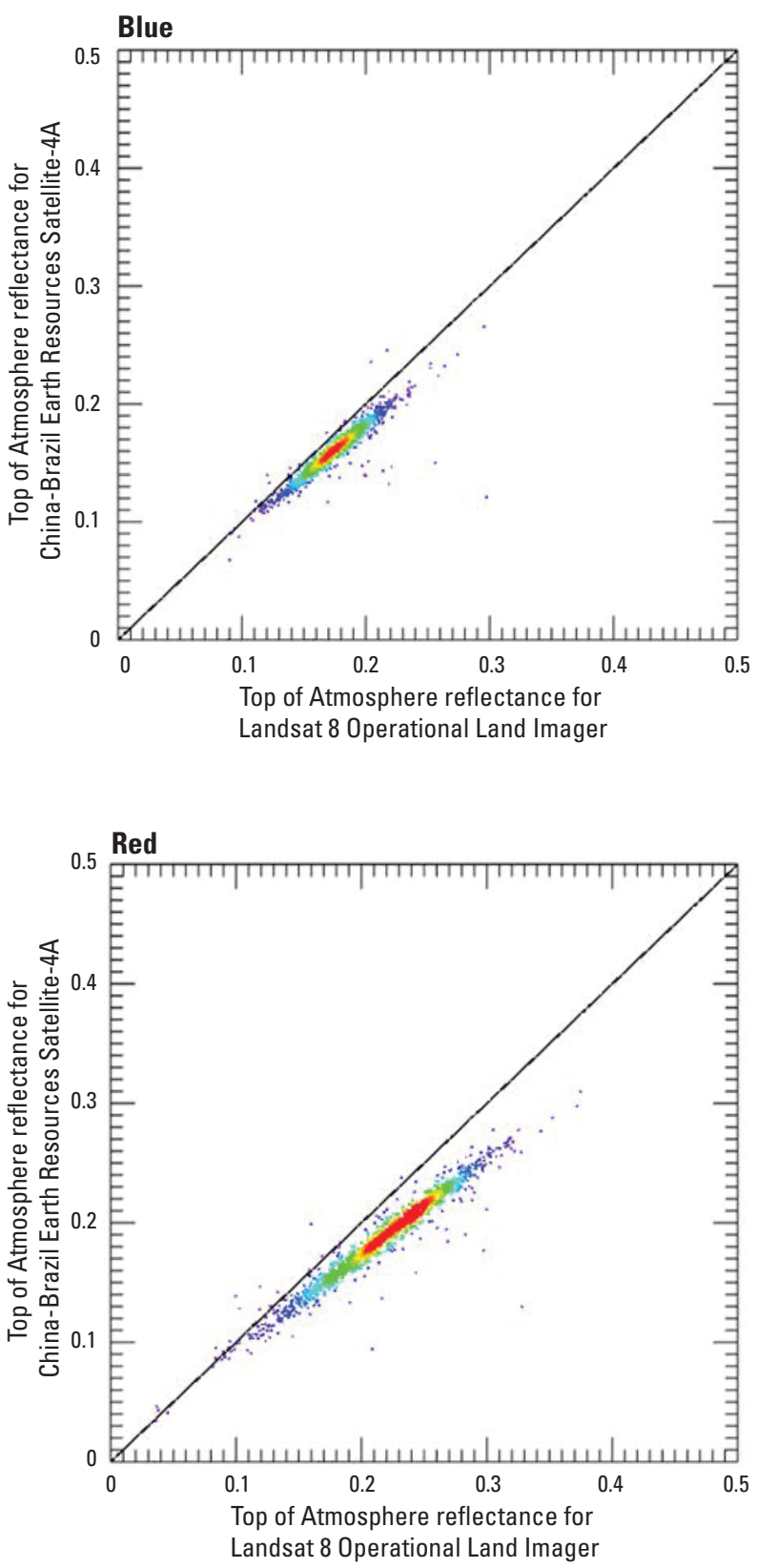

modulation transfer function at Nyquist frequency analysis output, as listed in table 7. The area selected within the Belo Horizonte scene for spatial analysis is shown in figure 32. For spatial analysis, we usually prefer to select edges along human-made features; however, at the CBERS-4A scale (16-m GSD) only agricultural fields, which have fairly straight edges, were large enough. We first searched the January and February summer (southern hemisphere) CBERS-4A scenes, but a lack of differences in the NIR band across field edges meant that no good fields could be identified for this analysis.
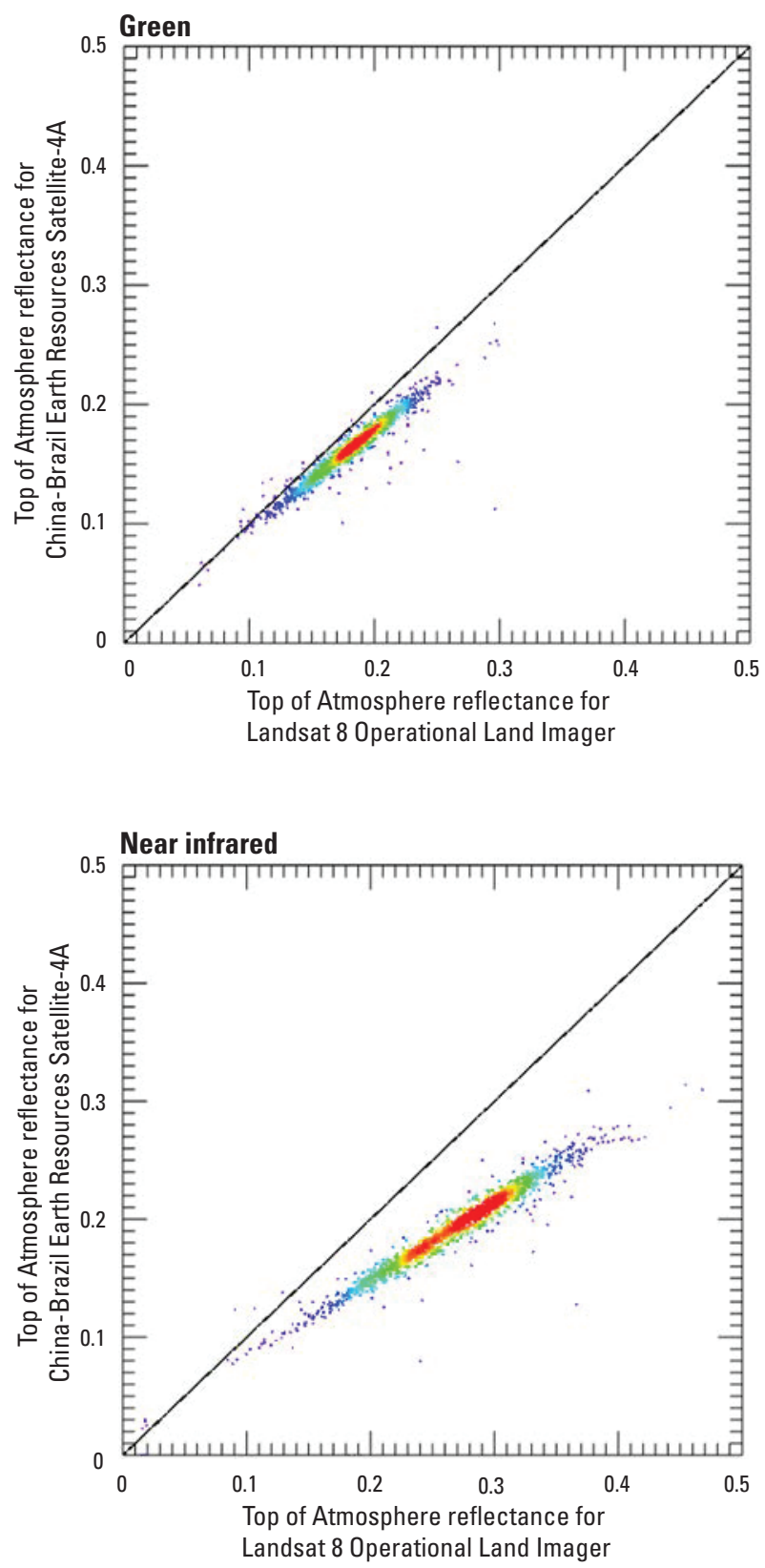

Figure 30. Top of Atmosphere reflectance comparison for Landsat 8 Operational Land Imager and China-Brazil Earth Resources Satellite-4A (Tacna, Peru). 

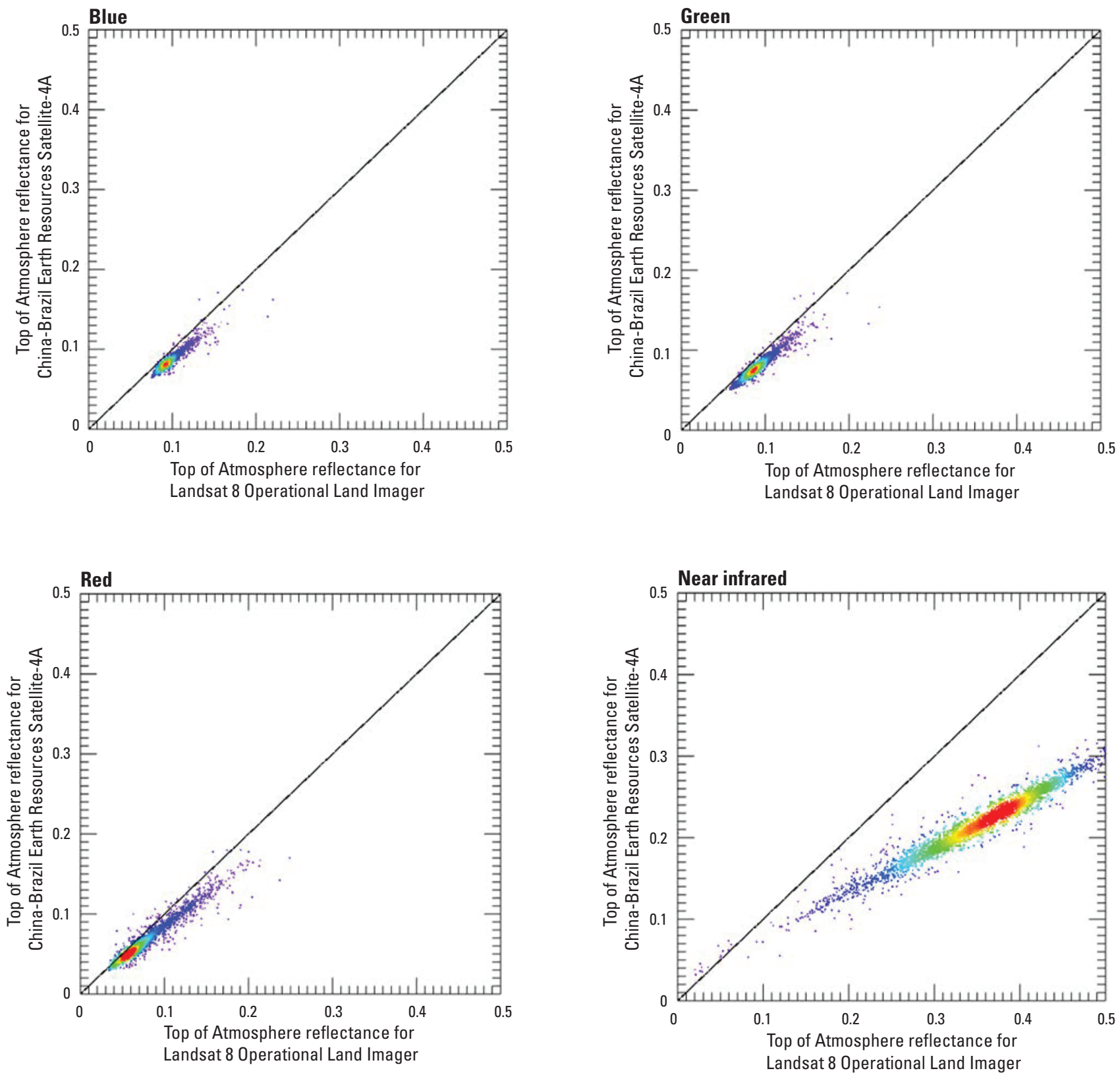

Figure 31. Top of Atmosphere reflectance comparison for Landsat 8 Operational Land Imager and China-Brazil Earth Resources Satellite-4A (Curitiba, Brazil). 
Table 6. Top of Atmosphere reflectance comparison of China-Brazil Earth Resources Satellite-4A against Landsat 8 Operational Land Imager.

[ID, identifier; NIR, near infrared; \%, percent; $R^{2}$, coefficient of determination; , about]

\begin{tabular}{llcccc}
\hline \multicolumn{1}{c}{ Scene ID } & \multicolumn{1}{c}{ Statistics } & Blue & Green & Red & NIR \\
\hline CBERS_4A_MUX_20200913_200_138_L4 & Uncertainty (\%) & 3.30 & 5.59 & 9.63 & 8.21 \\
LC08_L1TP_218074_20200913_20200919_02_T1 & $R^{2}$ & 0.941 & 0.953 & 0.966 & 0.929 \\
(Belo_Horizonte, Brazil) & Radical offset & -0.005 & 0.003 & 0.005 & 0.021 \\
& Radical slope & 0.916 & 0.855 & 0.825 & 0.648 \\
CBERS_4A_MUX_20200225_234_136_L4 & Uncertainty (\%) & 2.48 & 3.22 & 3.85 & 5.44 \\
LC08_L1TP_002073_20200225_20200822_02_T1 & $R^{2}$ & 0.939 & 0.946 & 0.95 & 0.941 \\
(Tacna, Peru) & Radical offset & -0.005 & -0.012 & -0.014 & -0.020 \\
Note: this image had 25\% ocean and clouds. A mask & Radical slope & 0.893 & 0.838 & 0.805 & 0.649 \\
was applied so these areas were not used for analysis. & Uncertainty (\%) & 2.90 & 4.12 & 9.38 & 9.51 \\
CBERS_4A_MUX_20200115_205_140_L4 & $R^{2}$ & 0.904 & 0.923 & 0.946 & 0.954 \\
LC08_L1TP_220075_20200115_20200823_02_T1 & Radical offset & -0.008 & -0.003 & -0.002 & -0.013 \\
(Curitiba, Brazil) & Radical slope & 0.967 & 0.898 & 0.842 & 0.578 \\
& & & & & \\
\hline
\end{tabular}

Table 7. Spatial performance of China-Brazil Earth Resources Satellite-4A.

[RER, relative edge response; FWHM, full width at half maximum; MTF, modulation transfer function; NIR, near infrared]

\begin{tabular}{|c|c|c|c|}
\hline Spatial analysis & RER & FWHM & MTF at Nyquist \\
\hline Band 5-blue & 0.44 & 2.38 pixels & 0.013 \\
\hline Band 6-green & 0.40 & 2.47 pixels & 0.003 \\
\hline Band 7-red & 0.40 & 2.52 pixels & 0.003 \\
\hline Band 8-NIR & 0.39 & 2.56 pixels & 0.001 \\
\hline
\end{tabular}




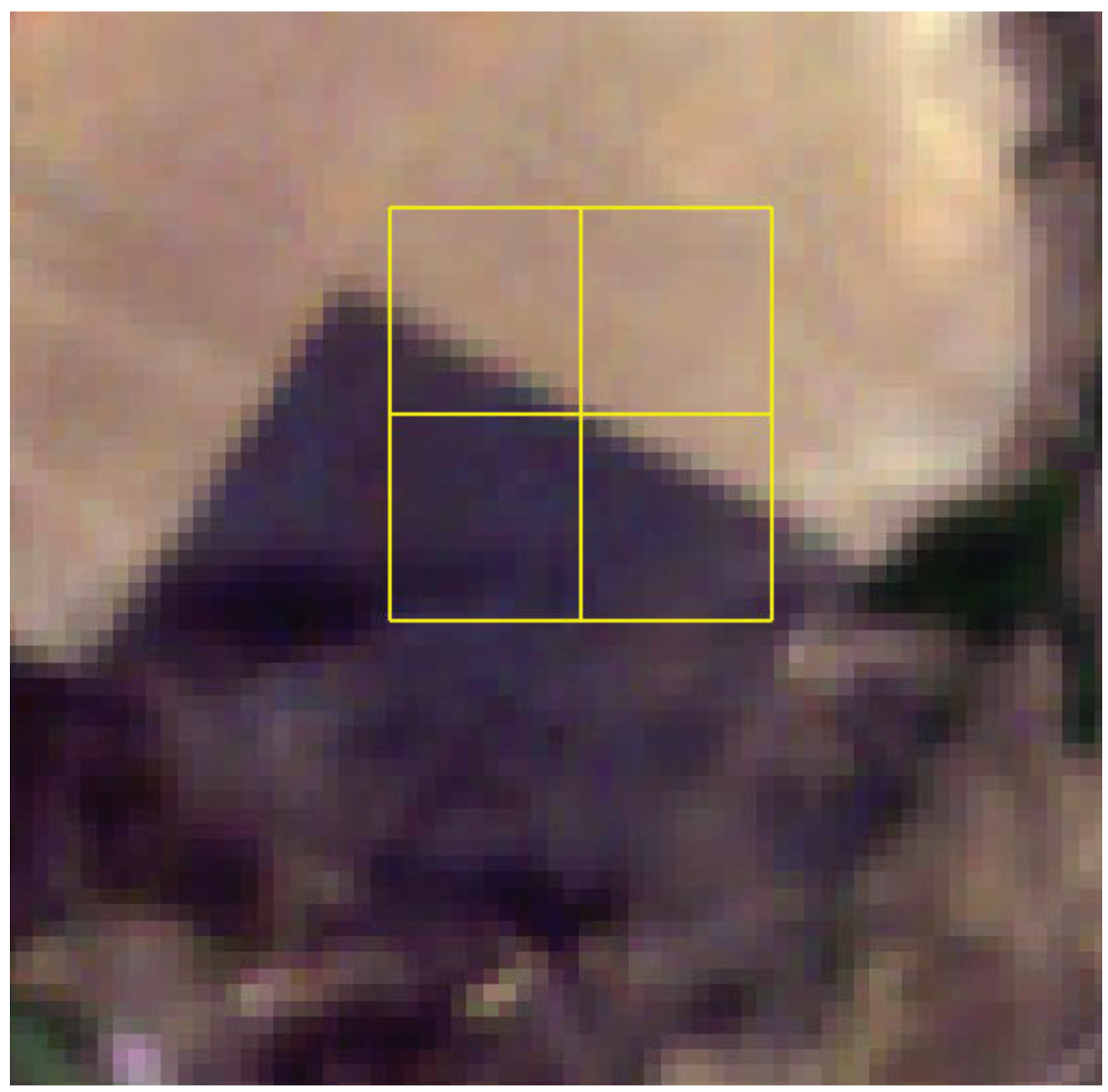

\section{EXPLANATION}

Grid showing the edge transect region of interest

Figure 32. China-Brazil Earth Resources Satellite-4A image region of interest selected for spatial analysis (Belo Horizonte, Brazil).

Therefore, we decided to look at agricultural fields in a September scene and selected a bare field that was spectrally different in all four bands compared to the adjacent field. The yellow box in figure 32 shows the edge transect region of interest.

The band 5 (blue) results are shown in figures 33 and 34. In figure 33, the dotted lines with diamond symbols are the raw transects. The green line is the middle transect, where the red dots are the region of the curve that is used for alignment. The lower plot in figure 33 is the aligned curve, and the green line represents edge spread function. In the upper plot in figure 34 , the white curve is the edge spread function, and the red line segment shows the relative edge response; the green curve is the line spread function, and the horizontal white line segment represents the full width at half maximum. The lower plot in figure 34 is the modulation transfer function to Nyquist frequency (0.5), and the dashed line shows the frequency corresponding to the 50-percent modulation transfer function value.

The results for band 6 (green) are shown in figures 35 and 36, the results for band 7 (red) are shown in figures 37 and 38 , and the results for band 8 (NIR) are shown in figures 39 and 40 . 


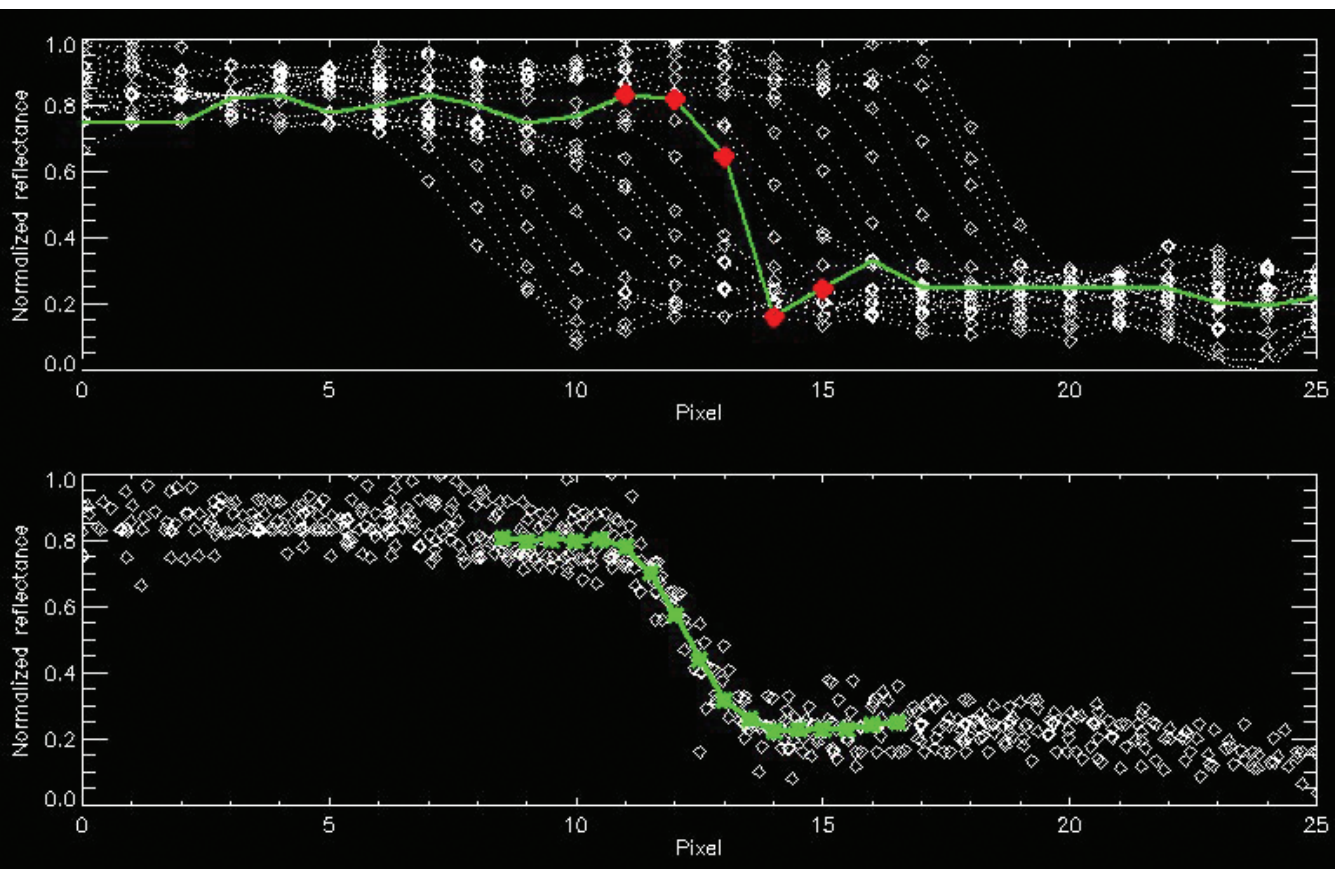

\section{EXPLANATION}

Middle transect-Dot indicates region of the curve used for alignment

\&. Raw transect

\section{EXPLANATION}

늘 Edge spread function

Aligned transect

Figure 33. Band 5 (blue) raw edge transects (upper) and aligned transects (lower).

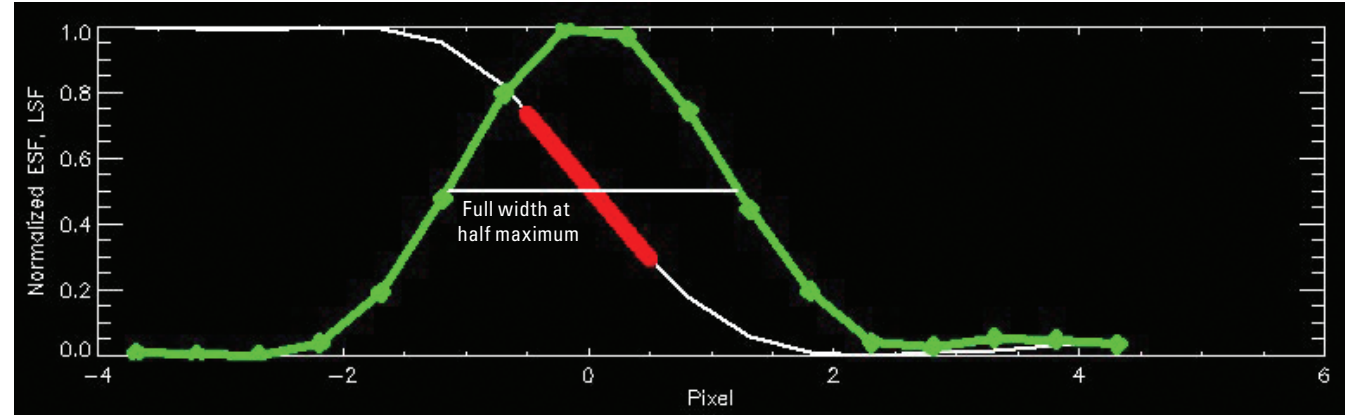

\section{EXPLANATION \\ Line spread function \\ Relative edge response \\ Edge spread function}

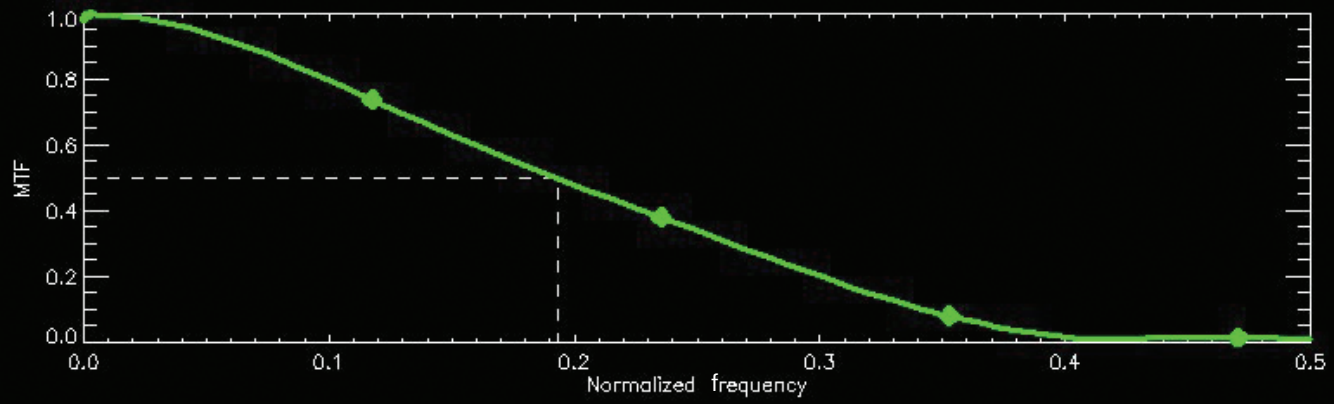

\section{EXPLANATION}

Modulation transfer function

Figure 34. Band 5 (blue) edge spread function (ESF) and line spread function (LSF; upper) and modulation transfer function (MTF; lower). 

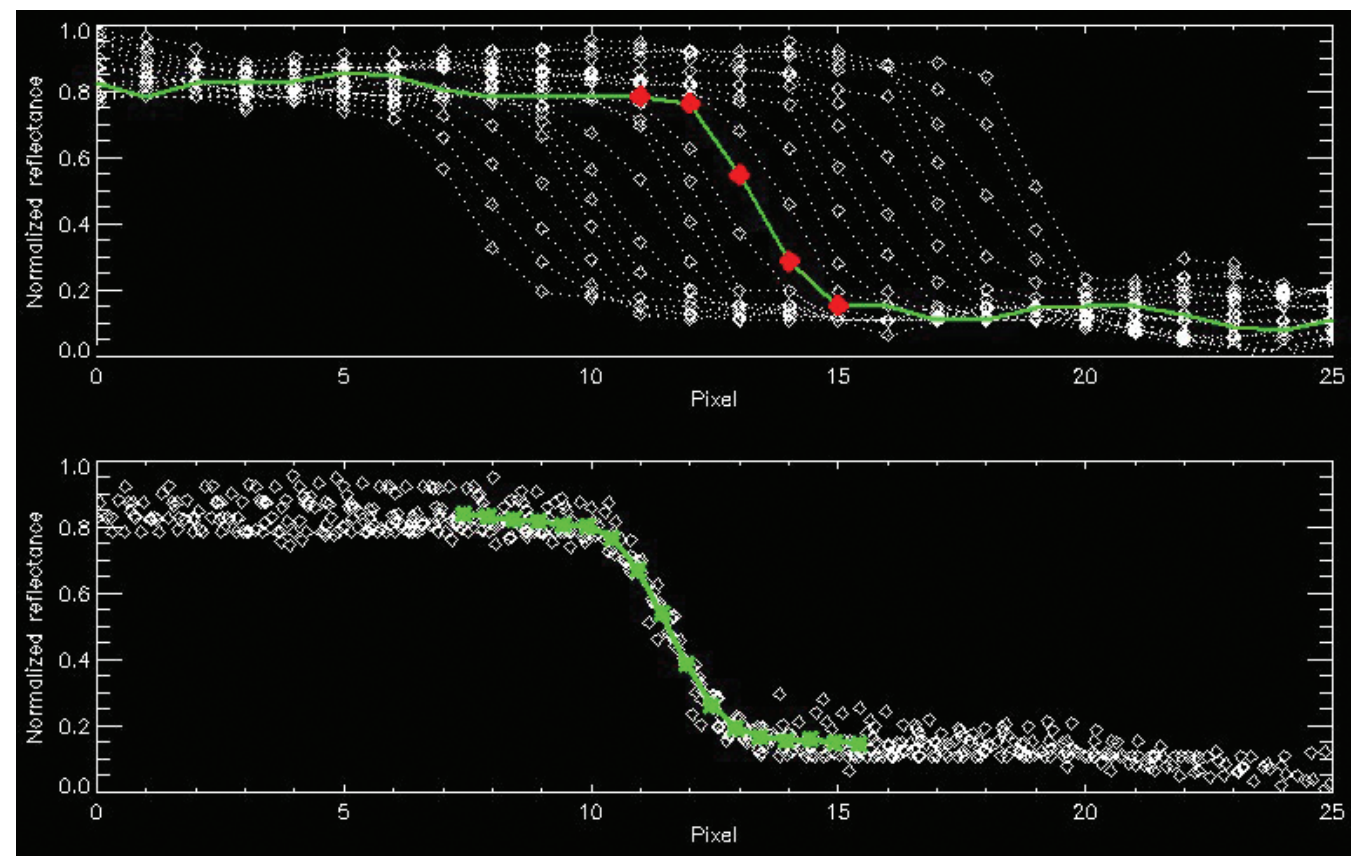

Figure 35. Band 6 (green) raw edge transects (upper) and aligned transects (lower).
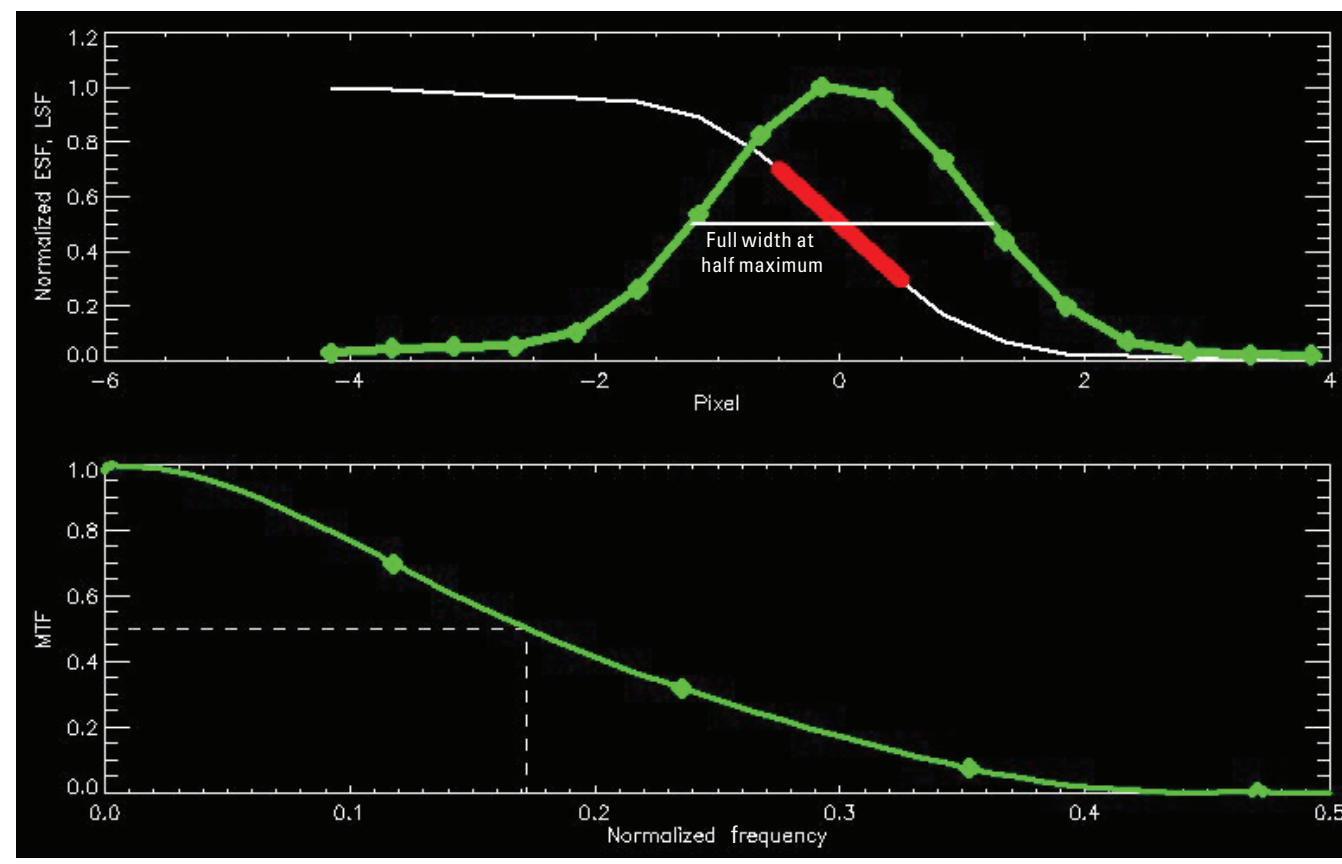

\section{EXPLANATION}

_ Middle transect-Dot indicates region of the curve used for alignment

\&. Raw transect

\section{EXPLANATION \\ - Edge spread function}

$\& \quad$ Aligned transect

Figure 36. Band 6 (green) edge spread function (ESF) and line spread function (LSF; upper) and modulation transfer function (MTF; lower). 


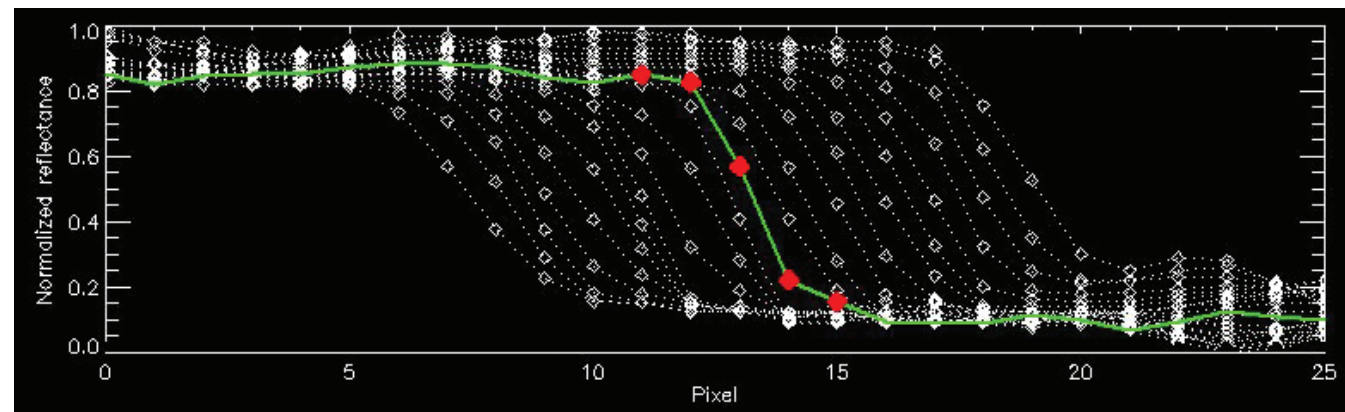

\section{EXPLANATION}

- Middle transect—Dot indicates region of the curve used for alignment

$\&$ Raw transect

\section{EXPLANATION}

- Edge spread function

$\$ \quad$ Aligned transect

Figure 37. Band 7 (red) raw edge transects (upper) and aligned transects (lower).
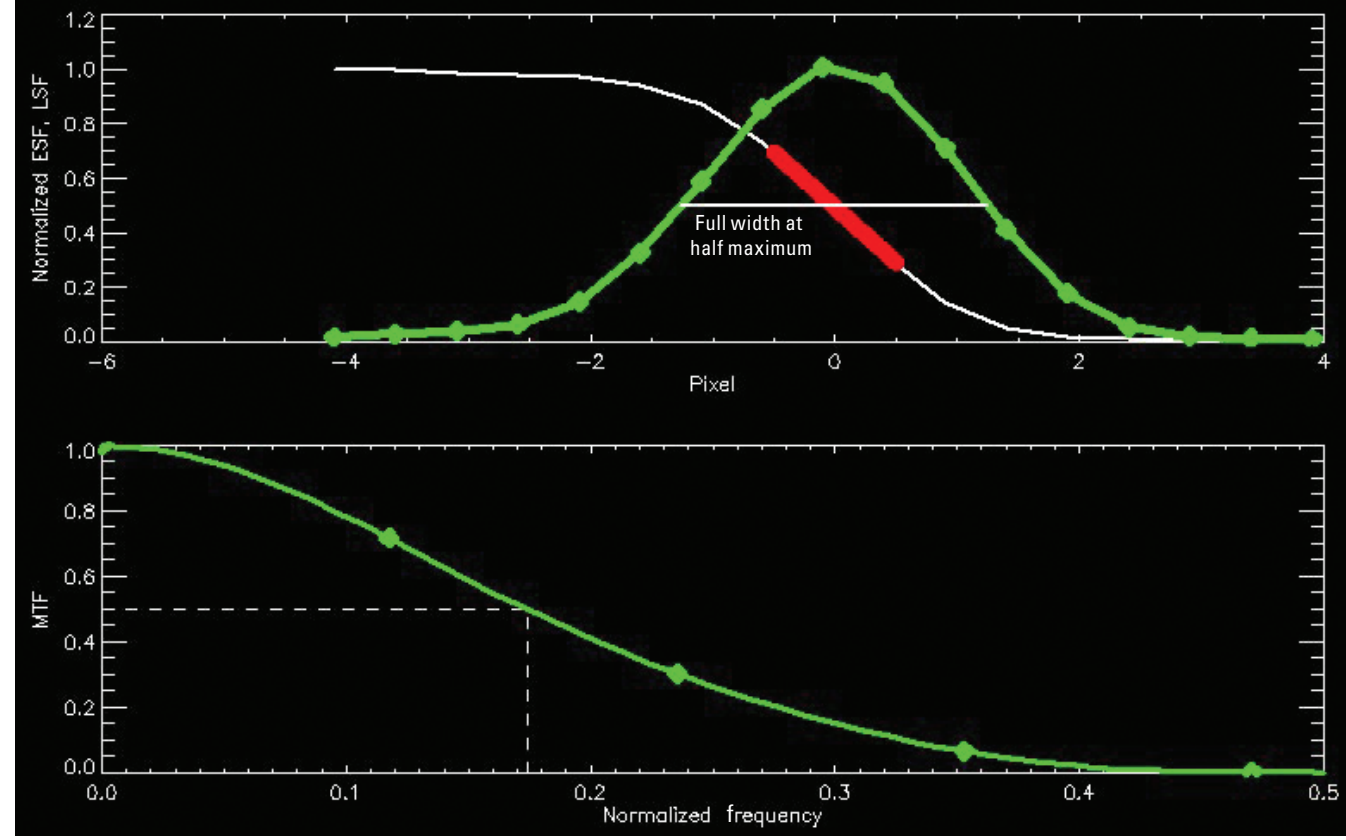

\section{EXPLANATION}

Line spread function

Relative edge response

Edge spread function

\section{EXPLANATION}

Modulation transfer function

- - Frequency corresponding to the 50-percent modulation transfer function value

Figure 38. Band 7 (red) edge spread function (ESF) and line spread function (LSF; upper) and modulation transfer function (MTF; lower). 


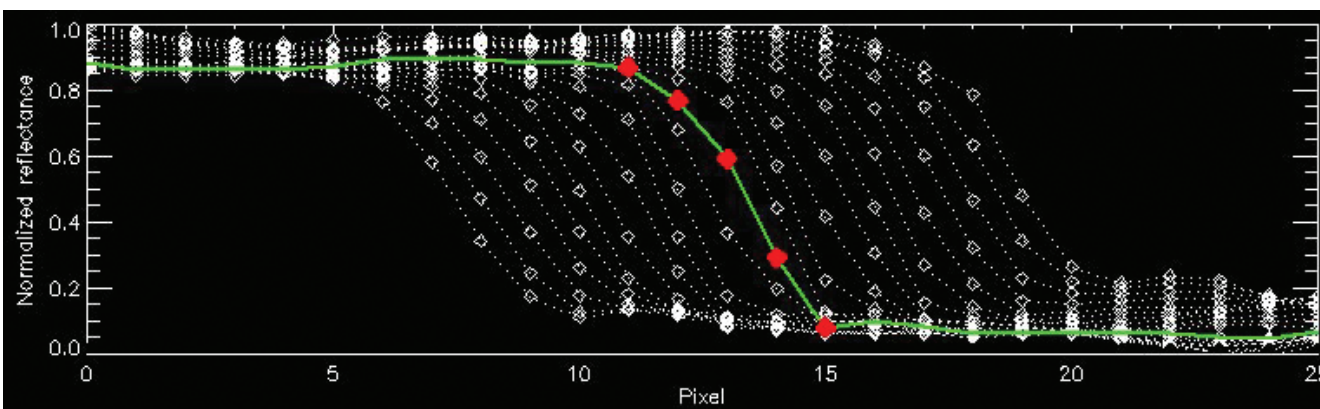

\section{EXPLANATION}

- Middle transect-Dot indicates region of the curve used for alignment

\&.. Raw transect

EXPLANATION

- Edge spread function

$\& \quad$ Aligned transect

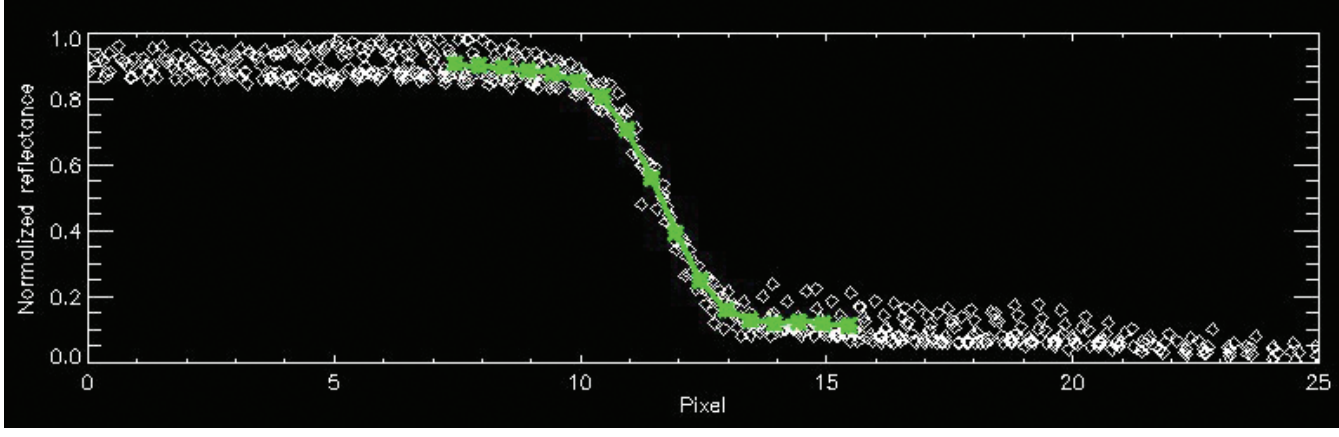

Figure 39. Band 8 (near infrared) raw edge transects (upper) and aligned transects (lower).
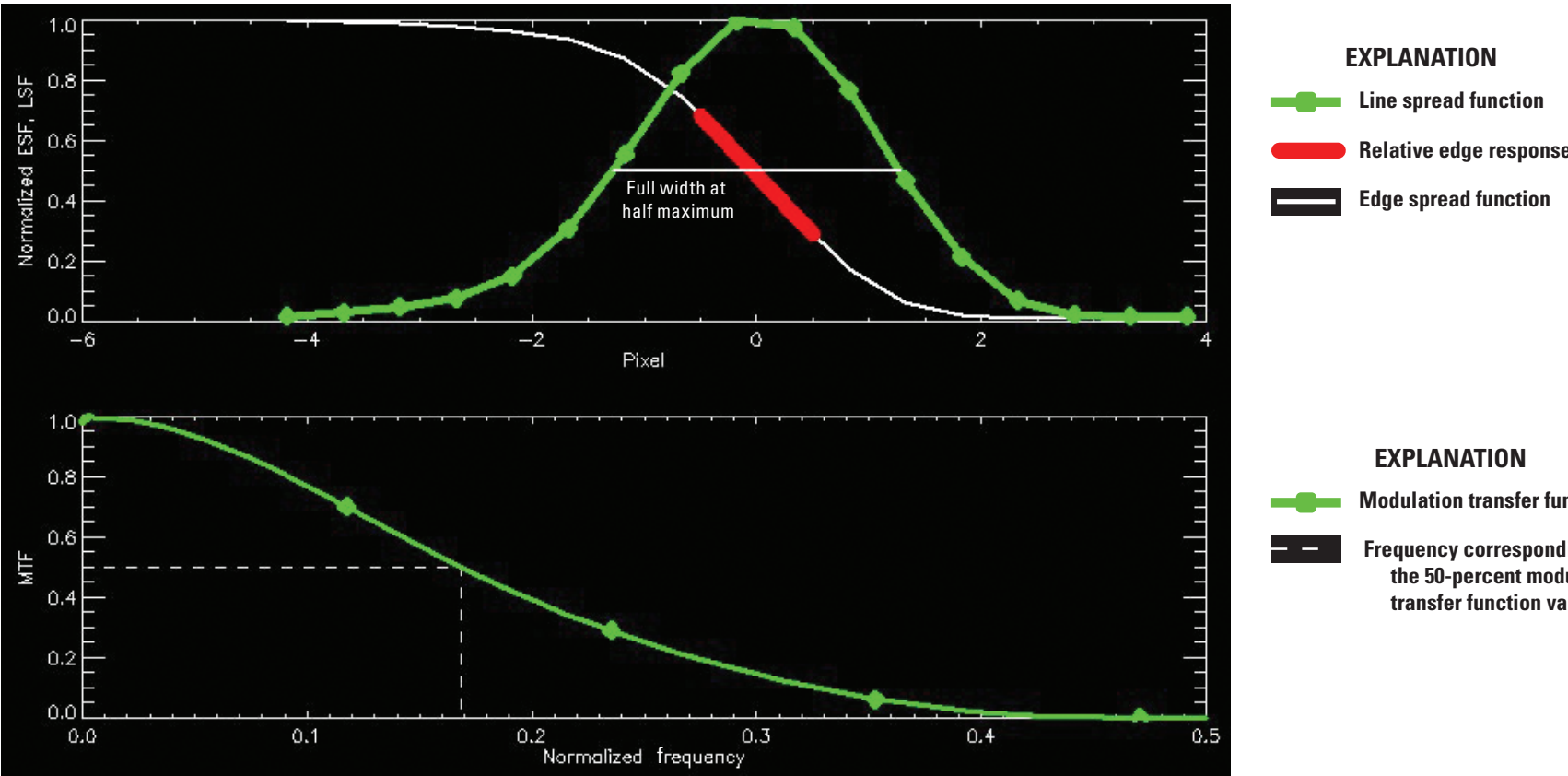

\section{EXPLANATION}

Modulation transfer function

Frequency corresponding to the 50-percent modulation transfer function value

Figure 40. Band 8 (near infrared) edge spread function (ESF) and line spread function (LSF; upper) and modulation transfer function (MTF; lower). 


\section{Summary and Conclusions}

This report summarizes the sensor performance of the China-Brazil Earth Resources Satellite-4A (CBERS-4A) sensor based on the U.S. Geological Survey Earth Resources Observation and Science Cal/Val Center of Excellence (ECCOE) system characterization process. In summary, we have determined that this sensor provides an interior (bandto-band) geometric performance in the range of -0.02 to -0.16 pixel; an exterior geometric accuracy performance of -22.02 ( -1.47 pixels) to -16.06 meters $(-1.07$ pixels); a radiometric accuracy performance of -0.006 to 0.925 (offset and slope); and a spatial performance for relative edge response in the range of 0.39 to 0.44 , for full width at half maximum in the range of 2.38 to 2.56 pixels, and for a modulation transfer function at a Nyquist frequency in the range of 0.001 to 0.013 .

In conclusion, the team has completed an ECCOE standardized system characterization of the CBERS-4A remote sensing system. Although we follow characterization procedures that are standardized across the many sensors and sensing systems under evaluation, these procedures are customized to fit the individual sensor, as we have done with CBERS-4A. The team has acquired the data, defined proper testing methodologies, carried out comparative tests against specific references, recorded measurements, completed data analyses, and quantified sensor performance accordingly. The team also endeavored to retain all data, measurements, and methods. This is key to ensure that all data and measurements are archived and accessible and that the performance results are reproducible.

The ECCOE project and associated Joint Agency Commercial Imagery Evaluation partners are always interested in reviewing sensor and remote sensing application assessments and would like to see and discuss information on similar data and product assessments and reviews. If you would like to discuss system characterization with the U.S. Geological Survey ECCOE and (or) the Joint Agency Commercial Imagery Evaluation team, please email us at eccoe@usgs.gov.

\section{Selected References}

European Space Agency, 2021, CBERS-4A: European Space Agency eoPortal web page, accessed June 2021 at https://directory.eoportal.org/web/eoportal/satellitemissions/c-missions/cbers-4a\#sensors.

National Institute for Space Research, 2020, CBERS 04A release: National Institute for Space Research web page, accessed June 2021 at http://www.cbers.inpe.br/ lancamentos/cbers04a.php.

Ramaseri Chandra, S.N., Christopherson, J.B., and Casey, K.A., 2020, 2020 Joint Agency Commercial Imagery Evaluation-Remote sensing satellite compendium: U.S. Geological Survey Circular 1468 (ver. 1.1, October 2020), 253 p. [Also available at https://doi.org/10.3133/cir1468.] [Supersedes USGS Circular 1455.]

U.S. Geological Survey, 2020a, EROS CalVal Center of Excellence (ECCOE): U.S. Geological Survey web page, accessed June 2021 at https://www.usgs.gov/core-sciencesystems/eros/calval.

U.S. Geological Survey, 2020b, EROS CalVal Center of Excellence (ECCOE)_JACIE: U.S. Geological Survey web page, accessed June 2021 at https:/www.usgs.gov/ core-science-systems/eros/calval/jacie?qt-science_support_ page_related_con $=3 \#$ qt-science_support_page_related_con.

U.S. Geological Survey, 2020c, Landsat missions-Glossary and acronyms: U.S. Geological Survey web page, accessed June 2021 at https:/www.usgs.gov/core-science-systems/ nli/landsat/glossary-and-acronyms. 

For more information about this publication, contact: Director, USGS Earth Resources Observation and Science Center 47914 252nd Street

Sioux Falls, SD 57198

605-594-6151

For additional information, visit: https://www.usgs.gov/centers/eros

Publishing support provided by the

Rolla Publishing Service Center 


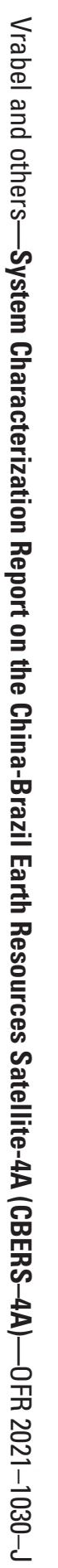

